This item was submitted to Loughborough's Research Repository by the author.

Items in Figshare are protected by copyright, with all rights reserved, unless otherwise indicated.

\title{
Projecting battery adoption in the prosumer era
}

PLEASE CITE THE PUBLISHED VERSION

https://doi.org/10.1016/j.apenergy.2018.01.056

PUBLISHER

(c) Elsevier

VERSION

AM (Accepted Manuscript)

PUBLISHER STATEMENT

This work is made available according to the conditions of the Creative Commons Attribution-NonCommercialNoDerivatives 4.0 International (CC BY-NC-ND 4.0) licence. Full details of this licence are available at: https://creativecommons.org/licenses/by-nc-nd/4.0/

\section{LICENCE}

CC BY-NC-ND 4.0

\section{REPOSITORY RECORD}

Barbour, Edward, and Marta Gonzalez. 2019. "Projecting Battery Adoption in the Prosumer Era". figshare. https://hdl.handle.net/2134/36989. 


\title{
Projecting battery adoption in the prosumer era
}

\author{
Edward Barbour ${ }^{\mathrm{a}}$, Marta C. Gonzalez*a,b,c \\ *corresponding author: martag@berkeley.edu \\ ${ }^{a}$ Department of Civil and Environmental Engineering, MIT, USA \\ ${ }^{b}$ Department of City and Regional Planning, UC Berkeley, USA \\ ${ }^{c}$ Lawrence Berkeley National Laboratory, USA
}

\begin{abstract}
Solar photovoltaic (PV) has the potential to make an important contribution to global sustainability, however, the misalignment between solar production and residential demand presents challenges for widespread PV adoption. Combining PV and storage is one way that this challenge can be overcome. In this work, we use one year of smart meter data from 369 consumers in three different US regions and calculate their economic benefits from both PV and coupled PV-battery systems. We consider a range of different electricity pricing schemes from the consumer regions, including both Feed-In-Tariff (FIT) and Net-Energy-Metering (NEM) policies. Significantly, our work uses real demand data, real PV generation data and optimizes each individual consumer's battery operation to minimize their electricity bill. Furthermore, we study the effect of batteries on consumer self-sufficiency, which is important because increasing self-sufficiency is a primary motivating factor behind battery adoption. We find that PV is profitable for the majority of consumers with most current pricing scenarios but PV-battery systems are always less profitable. However, batteries can provide very significant increases in self-sufficiency and we find that a majority of consumers can exceed $70 \%$ self-sufficiency with a $20 \mathrm{kWh}$ battery and a PV system that produces the equivalent of their consumption. This is compared to an average self-sufficiency of $35 \%$ with PV only. Finally, recognizing that a number of factors could lead to profitable batteries in future, we study the sensitivity of battery profitability to future electricity prices in a FIT scenario, also accounting for future decreases in PV and battery costs. We find that if PV-battery systems are to become better investments than PV-only for the majority of consumers, retail electricity prices above $\$ 0.40 / \mathrm{kWh}$ and FIT rates below $\$ 0.05 / \mathrm{kWh}$ are a likely requirement.
\end{abstract}

Keywords: Energy storage, residential batteries, rooftop PV, battery economics, prosumer self-sufficiency

\section{Introduction}

The electricity industry is the single biggest contributor to global greenhouse gas emissions worldwide [1] - in the US it accounts for $30 \%$ of total GHG emissions [2]. Of this, the US residential sector represents $36 \%$ of the nation's total electricity consumption [3] and is therefore an important area where emissions reduction can occur. Solar Photovoltaic (PV) panels are a popular way of reducing emissions via low-carbon solar-generated electricity, the uptake of which has been driven by many factors, including favorable policies, huge declines in the costs of PV panels and heightened public awareness of environmental issues. As a result, many different regions worldwide have experienced, or are currently experiencing, a boom in the levels of installed PV in the local distribution grid. For example,

Preprint submitted to Applied Energy at the end of 2015 California had over $10 \mathrm{GW}$ of installed solar, of which $3 \mathrm{GW}$ was installed in 2015 [4], while in Germany the installed PV capacity has recently surpassed $40 \mathrm{GW}$ (having been only $2 \mathrm{GW}$ in 2005) [5].

When electricity consumers install PV, they become "prosumers", producing electricity as well as consuming it. One primary challenge with PV "prosumption" is that the time of peak PV generation is mismatched with the typical peaks in residential electricity consumption. This misalignment has the potential to cause a number of operational problems for the electricity system if PV adoption becomes widespread [6]. These include increasing the required ramping rates for the grid [7], altering utilization factors for existing power plants [8], causing voltage and frequency reliability concerns $[9,10]$, and increasing wholesale electricity price fluctuations [11]. In areas with very high local rates of solar 


\begin{tabular}{|c|c|c|c|}
\hline \multicolumn{4}{|c|}{ Nomenclature } \\
\hline \multicolumn{2}{|l|}{ Acronyms } & $E_{i}^{G R}$ & $\begin{array}{c}\text { consumer } i \text { 's total grid imported } \\
\text { electricity }\end{array}$ \\
\hline FIT & Feed In Tariff & $E S_{i}(t)$ & $\begin{array}{l}\text { action of consumer } i \text { 's battery at } t \\
\qquad(\mathrm{kWh})\end{array}$ \\
\hline MILP & Mixed Integer Linear Program & $\mathrm{Li}$ & battery lifetime (years) \\
\hline NEM & Net Energy Metering & $N$ & Number of time periods \\
\hline NPV & Net present Value & $\mathrm{OM}$ & operation \& maintenance cost $(\$)$ \\
\hline TOU & Time Of Use & $\begin{array}{c}P(t) \\
P^{R, c h g}, P^{R, d i s}\end{array}$ & $\begin{array}{l}\text { battery power during } t(\mathrm{~kW}) \\
\text { battery rated charge/discharge }(\mathrm{kW})\end{array}$ \\
\hline \multicolumn{2}{|l|}{ Subscripts } & $S_{i}$ & $\begin{array}{l}\text { consumer } i \text { 's total yearly generation } \\
\qquad(\mathrm{kWh})\end{array}$ \\
\hline \multirow[t]{2}{*}{$i$} & for the $i$-th consumer & $S O C(t)$ & battery state of charge at $t(\mathrm{kWh})$ \\
\hline & & $\begin{array}{l}\operatorname{SOC}_{\min } / \\
\operatorname{SOC}^{\max }\end{array}$ & $\min /$ max battery state of charge $(\mathrm{kWh})$ \\
\hline \multicolumn{2}{|c|}{ Parameters and Variables } & $\triangle S O C(t)$ & $\begin{array}{l}\text { change in battery state of charge at } t \\
\qquad(\mathrm{kWh})\end{array}$ \\
\hline$\eta^{c h g} / \eta^{d i s}$ & $\begin{array}{l}\text { battery charging/discharging efficiency } \\
\qquad(\%)\end{array}$ & $S S_{i}$ & consumer $i$ 's self-sufficiency $(\%)$ \\
\hline$\pi(t)$ & $\begin{array}{l}\text { electricity price for grid import at } t \\
\qquad(\$ / \mathrm{kWh})\end{array}$ & $c_{i}(t)$ & consumer $i$ 's cost at $t(\$)$ \\
\hline$\pi^{E X}$ & reward for exported solar $(\$ / \mathrm{kWh})$ & $d_{i}(t)$ & demand of consumer $i$ at $t(\mathrm{kWh})$ \\
\hline$\pi^{b}(t)$ & $\begin{array}{l}\text { electricity buy price for the battery at } t \\
\qquad \$ / \mathrm{kWh})\end{array}$ & $r^{d}$ & discount rate $(\%)$ \\
\hline$\chi_{i}^{P V} / \chi_{i}^{P V B}$ & $\begin{array}{c}\text { consumer } i \text { total yearly electricity bill } \\
\text { with } \mathrm{PV} / \mathrm{PV}+\text { battery }(\$)\end{array}$ & $r^{i n f}$ & inflation rate $(\%)$ \\
\hline$B^{P V} / B^{B}$ & $\begin{array}{l}\text { Electricity bill saving due to } \\
\text { PV/Battery (\$) }\end{array}$ & $s_{i}(t)$ & $\mathrm{PV}$ generation of consumer $i(\mathrm{kWh})$ \\
\hline $\begin{array}{l}\operatorname{Cap}^{P V} / \\
\operatorname{Cap}^{B}\end{array}$ & $\begin{array}{c}\text { Capital costs of PV/PV+battery } \\
\text { installation }(\$)\end{array}$ & $t$ & time period (15-minute timestep) \\
\hline$C F(y)$ & net cash flow in year $y(\$)(\$)$ & $\Delta t$ & duration of time period $t$ \\
\hline$D_{i}$ & $\begin{array}{l}\text { consumer } i \text { 's yearly consumption } \\
\qquad(\mathrm{kWh})\end{array}$ & $y$ & year \\
\hline
\end{tabular}

PV adoption, the local daytime electricity demand may be reduced to such an extent that over-generation occurs, due to the minimum running requirements of local thermal power plants in the system [12]. This situation is exemplified by the CAISO (California Independent System Operator) solar "duck" curve.

These issues cause divergent opinions between prosolar groups and incumbent electric utilities, with prosolar groups focusing on the positive environmental aspects of PV and incumbent electric utilities on the operational challenges posed. In the US, a controversial issue is whether or not to preserve Net Energy Metering (NEM) [13] — which is currently the favored policy approach for residential PV in several US states. Under a NEM policy, consumers with PV installed are billed based on their net electrical usage, and surplus solar- generated electricity is rewarded at the same price per $\mathrm{kWh}$ as electricity from the grid would have cost at that time period. Alternatively, Feed In Tariffs (FITs) are the preferred approach in much of Europe. FIT policies usually oblige the local utility to buy all of a consumers surplus solar generation at a fixed export rate, which is specified by the relevant regulatory body. Both of these policies have been designed to promote investment in PV, however FIT rates are designed to be progressively reduced as target levels of capacity are achieved and surpassed. FIT agreements can also include provisions of payment for self-consumed electricity or limitations of the amount of electricity that is exported [14] and NEM is generally equivalent to a FIT for exported electricity which is equal to the retail electric rate at all times. It is also hugely important that as target levels of PV and 
target installation costs are achieved, regulatory support for PV is slowly fading [15].

Energy storage represents one solution to the challenges associated with intermittent solar generation [16, 6]. Storage can absorb surplus solar generation at times with low demand, releasing it at times with high demand. At a centralized scale for utilities, compressed air energy storage and pumped hydroelectric energy storage technologies are currently best placed to add value to wind or solar generation [17], however at the residential scale lithium-ion batteries are the most promising option [18]. Other promising storage technology options are under development, which include supercapacitors [19] and fuel cells, which are particularly interesting due to the potential to also provide heat [20], however at present batteries remain the only widely available option for residential-scale energy storage. Batteries also benefit from favorable public opinion a recent survey found that $78 \%$ of consumers approved of the idea of residential batteries [21] — and several companies are already marketing batteries to residential PV consumers. However, while customers favored the use of batteries to increase their self-sufficiency, saving money on electricity bills was the most important reason for battery adoption for the majority of residential consumers $[21,22]$.

Several recent studies have examined economics of residential batteries using a variety of methodologies. [23] examines the economics of battery storage using a single yearly electricity demand profile and a real PV electricity generation profile in the UK, optimizing the battery schedule using Mixed Integer Linear Programming (MILP) and finding that no battery is profitable with current UK flat electricity rates and "economy 7" tariffs. However the study suggests batteries may be profitable once costs fall below $£ 138 / \mathrm{kWh}$ and consumers are billed with wholesale prices. [24] uses hourly data from 36 real consumers to simulate 894 demand profiles and also simulates hourly PV generation for each consumer. The batteries are always scheduled for self-consumption and the study finds that batteries are profitable once the costs fall below $€ 214 / \mathrm{kWh}$ in a German context with current electricity prices. [25] considers a single Australian household with five different sizes of solar PV installation and a fixed battery size for each PV installation. The batteries are scheduled for self-consumption and different tariffs considered. For the demand profile studied, it was found that the payback periods were shorter for smaller PV systems. The study also calculated a reduction in $\mathrm{CO} 2$ emissions, however this did not include any potential emissions reduction for exported electricity, which was the primary reason that [26] found batteries lead to an increase in global emissions. Again with a focus on Australia, [27] considered the savings due to batteries under a range of real and hypothetical tariffs. The batteries were scheduled in a rule based manner rather than using an optimization and the study found that battery savings were greatest with high demand charges, however in all tariffs studied PV-only systems were generally better investments. [28] considers the effect of 2016 regulations regarding self-consumption in Spain on PV deployment and finds that the new regulation generally means that PV systems are economically infeasible for the majority of residential consumers, however they do not explicitly consider batteries. [29] compares profitability of PV-battery systems in Ireland and Germany, using 100 synthetic demand profiles in Germany and 100 real consumer loads in Ireland. Solar radiation was simulated using irradiance data and the batteries were scheduled to maximize self-consumption. It was found that PV-storage systems were profitable in Germany, although less profitable than PV-only. [30] considers 2104 hourly Swedish households using their batteries for maximum self-consumption. The work does not include an economic analysis and finds that there is minimal improvement in self-consumption by increasing battery capacities in $\mathrm{kWh}$ greater than four times the annual PV production in MWh.

The existing literature therefore does reach some general consensus on batteries. In particular, that batteries are currently less economic than PV-only systems, i.e. $[26,29,23,27]$, but that they may be economic in future scenarios where solar generation is largely unrewarded, wholesale prices are used and battery costs decrease, i.e. $[31,32,33,18,23]$. However, there are a number of areas which remain unexplored. Firstly, existing studies which have explicitly optimized each individual consumer's battery for bill minimization have considered few consumer demand profiles while studies that have considered many consumer demand profiles have used rule-based battery scheduling, for example, maximizing each consumer's self-sufficiency. Secondly, self-sufficiency and battery economics have not been linked when batteries are used for cost minimization. Thirdly, most existing studies have used simulated PV data if considering large numbers of demand profiles rather than outputs from real systems, which has been identified as a requirement for accurate economic estimations [23]. Fourthly, there is a gap in the knowledge surrounding at which electricity price levels there could be a boom in battery adoption for residential consumers, which is likely to occur when coupled PV-battery systems become more economic than standalone PV for the 
majority of residential consumers, and how this relates to future PV prices and future battery costs. Therefore, this paper seeks to address these areas through the following contributions:

- We consider how batteries can contribute to the self-sufficiency of 369 residential electricity consumers in the USA, using real demand and real PV generation data.

- We optimize the battery schedules for these consumers over the course of a year, explicitly for minimizing each consumer's electricity bill. To do this we formulate a novel method of optimizing battery schedule when a consumer's bill consists of the cost of electrical units with either a Feed In Tariff or Net Metering structure. This is applied for seven different electricity tariffs, including FIT and NEM structured tariffs, and a tariff based on variable wholesale electricity prices.

- We relate the Net Present Values of PV and battery systems to the tariff structures and consumer selfsufficiency.

- Under a FIT based tariff, which is suitable for widespread PV adoption, we investigate the potential for a boom in residential battery adoption by investigating at which price points the payback of coupled PV-battery systems is faster than PV-only for the majority of consumers. Furthermore, we consider the effect of future battery and PV installation costs.

Therefore, our work represents a robust study which systematically evaluates the conditions for a boom in residential battery deployment. We find that a battery boom is unlikely to occur if retail electricity prices remain below $\$ 0.40 / \mathrm{kWh}$ and rewards for exported solar are above $\$ 0.05 / \mathrm{kWh}$.

\section{Methods}

\subsection{Household demand and PV generation data}

For the demand data in our study, we exploit smart meter data from the Pecan Street project, which provides 15-minute resolution electricity data for in excess of 1000 consumers on a voluntary basis [34] and which is freely available for academic purposes. Firstly, we downloaded all the available total electrical usage data for households in the period 1st January 2015 to 31 st December 2015. After filtering for missing and erroneous data we select 369 consumers with a sufficiently complete year of consumption data for 2015. These consumers are located in three regions; 322 in Austin, TX, 33 in Boulder, CO, and 14 in San Diego, CA. Figures $1 \mathrm{a}$ and $1 \mathrm{~b}$ shows the demand and generation for a typical summer day in Austin.

We now need to model PV generation for each of these 369 demand profiles. While some of these consumers already have associated PV generation data, the exact amount of generation is inconsistent relative to their yearly demand, and therefore consumers cannot be compared regarding self-sufficiency or PV/battery profitability. Additionally, there are several consumers with valid PV generation but invalid demand - i.e. a complete year of PV generation but a significant amount of missing demand values. In order to allow general conclusions to be made, we ensure that the modeled generation for each consumer is equal to the sum of their yearly consumption. Previous work has typically considered fixed PV system sizes however this neglects that consumers are likely to size systems specific to their individual needs. As has been highlighted in previous work [24], the case of consumers installing solar generation which produces the equivalent of their yearly consumption is common and this is also likely to represent a limiting case in the event of widespread PV adoption. Furthermore, for consumers in the Pecan Street data who do have both complete demand and generation data the ratio of total-consumption to total-PV-generation is typically within the range $0.4-1.4$, thus providing further justification. We find that in the consumer regions, there are 198 generation profiles which contain a complete year of data, however many of these contain data from faulty PV installations. To filter out faulty systems, we look at the ratio of each PV system's peak installed power to total yearly electrical output and compare this to the result from a simulated $5 \mathrm{~kW}$ rooftop system in each region. The results are shown in Figure 1c for Austin and we highlight the predicted $5 \mathrm{~kW}$ system result (the average size for a U.S. residential installation), which is simulated using the NREL PVWatts calculator $^{1}$, a state-of-the-art predictor for PV output. Most systems are centered around a straight line showing that, in general, each $\mathrm{kW}$ of installed PV produces a similar amount over the year. However, we find that several systems have a much higher 15-minute peak power than we would expect for their yearly generation and we filter these out as faulty, only including any system within $25 \%$ from the line suggested by the simulated $5 \mathrm{~kW}$ system as feasible for modeling (see Figure 1c).

\footnotetext{
${ }^{1}$ http://pvwatts.nrel.gov/
} 

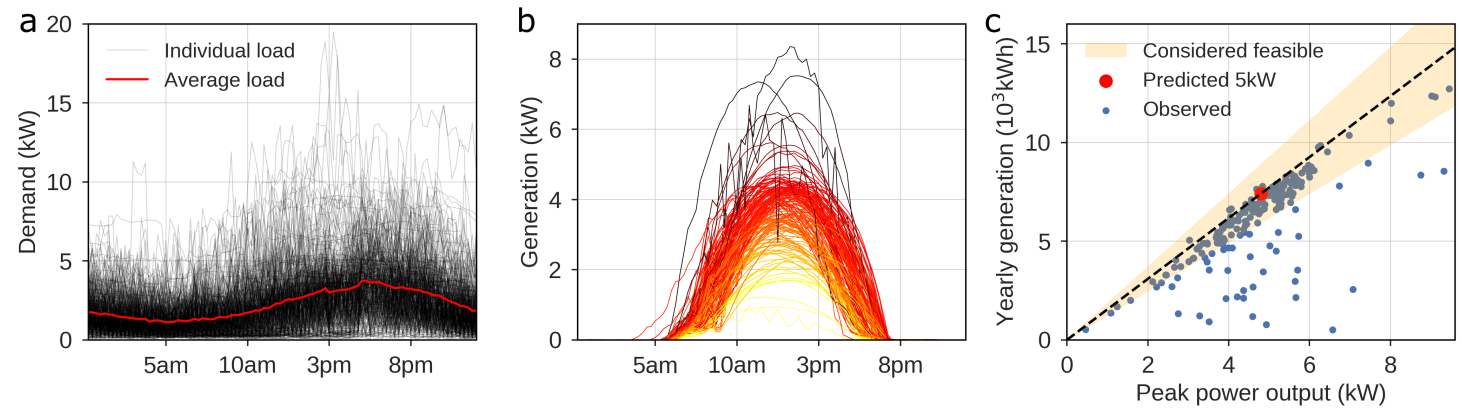

Figure 1: Demand and generation data. (a) 15-minute demand on a summer day. (b) Solar generation data on the same day. (c) Yearly generation against peak power for solar data in Austin. The red dot shows the NREL predicted 5kW output and the highlighted region illustrates which systems a consumer can be assigned in our study.
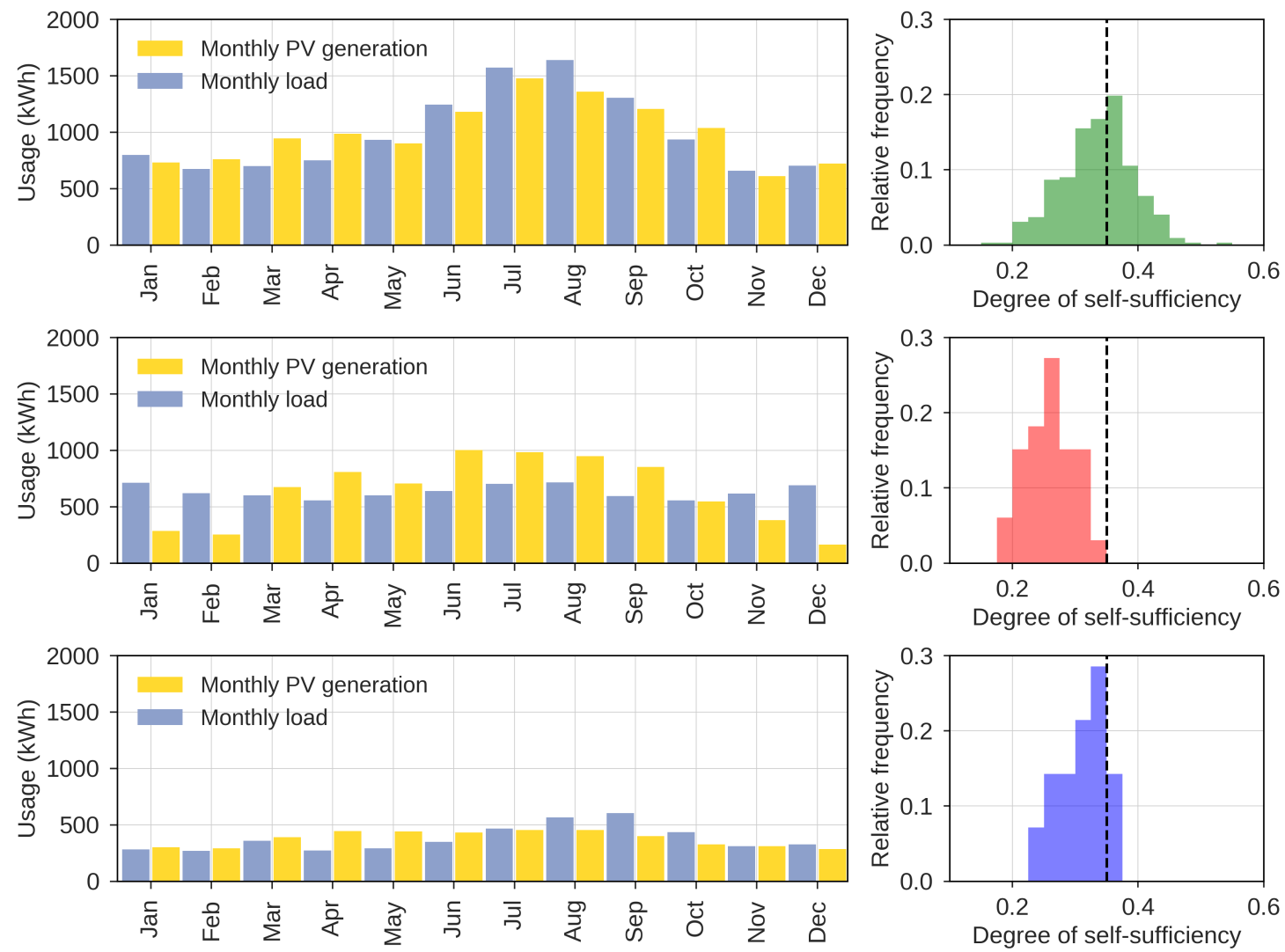

Figure 2: Demand and generation data. (a) Average monthly demand and simulated generation for consumers in Austin. (b) Self-sufficiency without batteries of Austin consumers (c) Average monthly demand and simulated generation Boulder. (d) Self-sufficiency of Boulder consumers (e) Average monthly demand and simulated generation for the San Diego consumers. (f) Self-sufficiency of San Diego consumers. The dotted line shows the median self-sufficiency for all the consumers (35\%).

To complete the process for simulating generation, each consumer $i$ is randomly assigned the generation from an acceptable PV system in their respective region (Austin, Boulder or San Diego), or if there is no PV system without faults consumers are assigned the predicted
$5 \mathrm{~kW}$ system output. In the San Diego region, there is no suitable PV data so all consumers are assigned the predicted $5 \mathrm{~kW}$ output. Every observed generation value is then multiplied by a factor $\frac{D_{i}}{S_{i}}$, where $D_{i}$ is the consumers total annual demand and $S_{i}$ is the total genera- 
tion of their PV system. This scales the generation from the randomly selected PV system for each consumer so that the total generation is equivalent to the consumer's total yearly electric consumption and representative of their local solar resource.

With PV modeled for each prosumer $i$, we can then define their base self-sufficiency (without battery) as:

$$
S S_{i}=\frac{D_{i}-E_{i}^{G R}}{D_{i}}
$$

This is consistent with [24, 14]. Here, $D_{i}$ is consumer $i$ 's total yearly electricity demand and $E_{i}^{G R}$ is the total electricity they import from the grid. If a prosumer's demand were perfectly aligned with their PV generation they would be entirely self-sufficient and have $S S_{i}=$ 1. Figure 2 shows average monthly consumption and generation and the base self-sufficiency for consumers in each location. We observe that the median degree of self-sufficiency for all consumers is $35.5 \%$, which is similar to estimates of 30-37\% for households in Europe [24].

\subsection{Battery model}

We propose a battery model based on current lithium based batteries available to residential consumers for use with PV, similar to those made by Tesla ${ }^{2}$, Iron Edison $^{3}$ and Ampetus energy ${ }^{4}$. Typically these batteries have high efficiency (quoted 85-95\%), capacities in the range $2-20 \mathrm{kWh}$, guaranteed lifetimes between 20005000 cycles and total capital system costs in the range $\$ 400-700 / \mathrm{kWh}$. In our simulations we model batteries with an average round trip efficiency of $85 \%$ over their lifetime which can charge at a rate of $0.5 \mathrm{C}$. This means that if the battery has a capacity of $1 \mathrm{kWh}$ the maximum charging and discharging rates are $0.5 \mathrm{~kW}$. We assume a lifetime of 3000 cycles at $85 \%$ depth-of-discharge.

To schedule each consumer's battery, we consider that the battery is used to minimize the the cost of the consumer's electricity bill and optimize the schedule of operation of each consumer's battery explicitly for this purpose. The model accounts for the physical capacity of the battery, charging and discharging limits, cycle life and losses during the charging and discharging processes. To schedule the operation of each consumer's battery we adapt a previous algorithm first used to optimally schedule Pumped Storage plants [35].

\footnotetext{
${ }^{2}$ https://www.tesla.com/powerwall

${ }^{3}$ https://ironedison.com/

${ }^{4}$ http://www.ampetus.com.au/superlithium/
}

With a PV installation and battery, a consumer's net electrical demand at any time period $t$ can be expressed as $d_{i}(t)-s_{i}(t)+E S_{i}(t)$, where $d_{i}(t)$ is consumer $i$ 's actual demand, $s_{i}(t)$ is their solar generation and $E S_{i}(t)$ is the action of their battery. We assume that a consumers' electricity bill is composed entirely of the price of electrical units of energy, rather than other charges (for example charges relating to peak power usage or fixed charges), and consider billing arrangements which can have either a Net Energy Metering (NEM) or a Feed In Tariff (FIT) structure. The price for electricity bought from the power network is $\pi(t)$ and under a NEM policy the consumer is charged for the net cost of the energy that they use at each period, as implied by Equation 2 .

$$
c_{i}(t)=\left[d_{i}(t)-s_{i}(t)+E S_{i}(t)\right] \pi(t)
$$

The net demand $\left[d_{i}(t)-s_{i}(t)+E S_{i}(t)\right]$ can be either positive or negative at each period, where a negative net demand represents electricity exported to the grid. If the user exports sufficient power to the grid their total cost may be negative - implying a reimbursement rather than a payment for their electricity bill. Under the FIT strategy, PV generation used locally displaces the need to buy grid electricity, and exported electricity is rewarded at the FIT export rate $\left(\pi^{E X}\right)$. Therefore the cost at each period depends on whether energy is being imported or exported and is expressed conditionally by Equations 3 and 4 respectively.

$$
\begin{gathered}
\operatorname{IF} d_{i}(t)+E S_{i}(t) \geq s_{i}(t) \\
c_{i}(t)=\left[d_{i}(t)-s_{i}(t)+E S_{i}(t)\right] \pi(t) \\
\operatorname{ELSE~IF~} d_{i}(t)+E S_{i}(t)<s_{i}(t) \\
c_{i}(t)=\left[d_{i}(t)-s_{i}(t)+E S_{i}(t)\right] \pi^{E X}
\end{gathered}
$$

The operation of the battery module is then driven by the prices $\pi(t)$ and $\pi^{E X}$ and minimizing a consumer's electricity bill is expressed by minimizing the objective function representing the consumer's total electricity cost over the entire year, as shown in Equation 5.

$$
\text { Minimize : } \sum_{t=0}^{t=N} c_{i}(t)
$$

Inspecting Equations 2, 3 and 4, the only variable is $E S_{i}(t)$, the action of consumer $i$ 's battery. Therefore this is the decision variable. It should be noted that this cost function assumes that all of a consumer's demand $d_{i}(t)$ must be met, i.e. $c_{i}(t)$ is the cost of meeting this demand at period $t$.

The minimization is constrained by the equations which represent the physical limits of the battery, given 
by Equations 6, 7, 8, 9 and 10, and the additional constraints specified in Equations 11 and 12.

The equation which governs the battery's State Of Charge $(S O C)$ is described by Equation 6.

$$
\operatorname{SOC}(t)=\operatorname{SOC}(t-1)+\Delta t P(t)
$$

Here $t$ is the time, $P(t)$ is the charging or discharging power of the storage (where $P(t)>0$ implies charging and $P(t)<0$ implies discharging) and $\Delta t$ is the time between $t$ and $t+1$. The limits on $S O C(t)$ constrain that the energy stored within the battery must be between the minimum and maximum stored energy limits, as shown by Equation 7.

$$
S O C^{\min } \leq S O C(t) \leq S O C^{\max }
$$

The charging and discharging power is also constrained by the charging and discharging limits of the battery, as described by Equation 8 .

$$
P^{R, d i s} \leq P(t) \leq P^{R, c h g}
$$

$P^{R, d i s}$ is the maximum rate at which energy is removed from the battery and $P^{R, c h g}$ is the maximum rate of energy addition. Due to the efficiency of the charging and discharging processes, the actual energy required $E S(t)$ to deliver an addition of $P(t) \Delta t$ to the battery (where $P(t)>0$ ) is given by Equation 9 .

$$
\begin{aligned}
& \operatorname{IF} P(t) \geq 0 \\
& E S(t)=\frac{\Delta t P(t)}{\eta^{c h g}}=\frac{\Delta S O C(t)}{\eta^{c h g}}
\end{aligned}
$$

As we always consider fixed width time periods (width $=\Delta t=15 \mathrm{~min}$ ), we introduce $\Delta S O C(t)=P(t) \Delta t$, the amount of energy added during time period $t$. Similarly, the actual energy released $E S(t)$ when an amount $\triangle S O C(t)$ (where $\triangle S O C(t)<0$ ) is removed from the battery is given by Equation 10 .

$$
\begin{aligned}
& \operatorname{IF} P(t)<0 \\
& E S(t)=\Delta t P(t) \eta^{d i s}=\Delta S O C(t) \eta^{d i s}
\end{aligned}
$$

From Equations 9 and 10 it is immediately apparent that any charge-storage-discharge process will result in a fractional energy loss of $\left(1-\eta^{\text {chg }} \eta^{d i s}\right)$.

Importantly, we add further constraints so that the battery cannot be used to actively participate in market arbitrage - i.e. selling electricity back to the grid at price $\pi(t)$ or the export price $\pi^{E X}-$ it can only be used to move consumption from one period to another. This adds the further constraints:

$$
\begin{aligned}
& \operatorname{IF} s_{i}(t) \leq d_{i}(t) \\
& E S_{i}(t) \geq s_{i}(t)-d_{i}(t) \\
& \operatorname{ELSE~IF~} s_{i}(t)>d_{i}(t) \\
& E S_{i}(t) \geq 0
\end{aligned}
$$

Explicitly, Equation 11 means that if there is some net consumer demand at time $t$, the battery cannot output more than this demand, as to do so would necessitate that some discharged energy would be exported to the grid. Equation 12 means that if the consumer is exporting solar generation at time $t$ then the battery can only charge.

To perform the minimization we assume the electricity price and the consumer demand are known throughout the optimization period, which is a full year. Strictly speaking, this leads to a result which corresponds to the maximum possible yearly saving from the battery. However, residential electricity prices are typically specified years into the future and furthermore, while unpredictable consumer demand reduces the ability to optimize the storage schedule, we note that the batteries typically operate on a daily cycle and thus typically the demand forecast must only be accurate within a 24-hour period. As a result, the saving will only be affected if the demand is sufficiently different to the predicted demand that the battery cannot operate at another period with the equivalent electricity price - and residential tariffs generally have large time windows of constant electricity price. For other storage applications, i.e. minimizing peak demand related charges or easing grid congestion, the effects of imperfect forecasts are much more important.

Several methods of scheduling the optimum operation of the battery exist. The simplest case corresponds to a time-independent price for grid electricity $\pi(t)=\pi$ and a reward for exported solar electricity $\pi^{E X}$ satisfying Equation 13.

$$
\pi>\frac{\pi^{E X}}{\eta^{\text {chg }} \eta^{d i s}}
$$

In this case, a prosumer can save money by forfeiting the reward for exported solar electricity, storing it and using it to replace grid-bought electricity. The optimum schedule simply corresponds to maximizing the local usage of PV generation which can be achieved with a simple rule-based strategy. This strategy charges the battery at the maximum allowable rate (the minimum 
of the maximum charging ability in that period or the amount of exported solar electricity) when there is solar that would otherwise be exported until the battery is fully charged, and subsequently discharges at the minimum allowable rate (the maximum of the minimum discharging ability in that period or minus the local demand met by grid-bought electricity) when the solar generation can no longer meet all the local demand until the battery is empty. Here we use the notation convention that discharging is negative, hence the minimum discharge rate is that with the largest magnitude. This is sometimes referred to as cycle charging and the operation rules are described in Equations 14, 15, 16 and 17.

$$
\begin{aligned}
& \text { IF } s_{i}(t)>d_{i}(t) \text { AND } t==0 \\
& E S_{i}(t)=\operatorname{MIN}\left[s_{i}(t)-d_{i}(t), \frac{P^{R, c h g}}{\eta^{c h g}}, \frac{S O C^{\max }}{\eta^{\text {chg }}}\right] \\
& \text { ELSE IF } s_{i}(t)>d_{i}(t) \text { AND } t>0 \\
& E S_{i}(t)=\operatorname{MIN}\left[s_{i}(t)-d_{i}(t), \frac{P^{R, c h g}}{\eta^{\text {chg }}},\right. \\
& \left.\frac{S O C^{\max }-S O C(t-1)}{\eta^{\text {chg }}}\right] \\
& \text { ELSE IF } d_{i}(t) \geq s_{i}(t) \text { AND } t==0 \\
& E S_{i}(t)=0 \\
& \text { ELSE IF } d_{i}(t) \geq s_{i}(t) \text { AND } t>0 \\
& E S_{i}(t)=\operatorname{MAX}\left[s_{i}(t)-d_{i}(t), P^{R, d i s} \eta^{d i s},\right. \\
& \left.\left(S O C^{\min }-S O C(t-1)\right) \eta^{d i s}\right]
\end{aligned}
$$

The battery state of charge $S O C(t)$ is governed by Equation 6. This approach for scheduling the batteries is used in a number of papers, including [24, 29, 30, 36]. Using cycle charging to schedule the batteries is advantageous as it is easy to compute, however when the price function has a time varying component it does not correspond to to the optimum schedule for bill minimization. As a result, papers which explicitly optimize the consumer's schedule for electricity bill minimization often make use of optimization software packages, for example CPLEX as used in [23].

In this paper, to schedule consumer batteries explicitly for bill minimization, we adapt the algorithm developed in [35] which was originally used to schedule the operation of pumped hydroelectric energy storage plants with wholesale electricity prices. The operation of our algorithm is described as follows:

1. The algorithm starts with time series of consumer $i$ 's demand $d_{i}(t)$, generation $s_{i}(t)$ and the electricity prices $p(t)$. The battery properties are specified and the schedule of operation $E S(t)$ is initialized to zero at all time periods. Boolean variables for charging and discharging is created and initialized to one at all time periods.

2. A buy price for electricity $\pi^{b}(t)$ is then defined, which depends on the pricing policy. Under a NEM policy the buy price is set equal to the grid electricity price at all times, i.e. $\pi^{b}(t)=\pi(t)$ $\forall t$. If the pricing policy has a FIT structure then the buy price is set equal to the FIT rate $\pi_{E X}$ for all times when solar is being exported, i.e. IF $d_{i}(t)+E S_{i}(t)-s_{i}(t)<0$ then $\pi^{b}(t)=\pi_{E X}$ and IF $d_{i}(t)+E S_{i}(t)-s_{i}(t) \geq 0$ then $\pi^{b}(t)=\pi(t)$.

3 . The algorithm searches the time-series of grid electricity prices, $\pi(t)$ available for battery discharging, as marked by the Boolean variable for discharging. The time of the highest price is denoted MAXhour.

4. A range around MAXhour in which it is physically possible for the device to charge is established. This range spans between the last time before MAXhour that the battery was fully charged and the time period before the last period after MAXhour (including MAXhour) when the battery was empty. If there are no times before MAXhour when the battery was fully charged then the start of the range is simply the first time period.

5. The minimum price within this range in the electricity buy-price timeseries, $\pi^{b}(t)$, available for charging as marked by the Boolean variable for charging is located and denoted MINhour.

6. The cost of operating the battery between MINhour and MAXhour is calculated and if it results in a net cost reduction for the consumer then the operation is added to the battery's schedule at the maximum level that doesn't violate any constraints, specifically those specified by Equations 6, 7, 8, $9,10,11$ and 12 . If there is no cost reduction then the Boolean variable for discharging availability is set to zero at MAXhour.

7. The algorithm then checks if the battery operation is at the maximum allowed level at either MAXhour or MINhour and if so sets the Boolean variables for discharging and charging availability respectively to zero.

8. Finally the buy price timeseries is updated to include the action of the consumer's battery, $E S_{i}(t)$, i.e. if all the surplus solar has been used at a particular period the buy price is updated to reflect the grid cost, i.e. $\pi^{b}(t)$ is changed from $\pi_{E X}$ to $\pi(t)$. The process 2-6 is repeated until the Boolean variable for discharging availability has all entries equal to zero. 
A flowchart outlining the algorithm operation is shown in Appendix A, which also demonstrates the algorithms results for three representative test cases.

\subsubsection{Algorithm performance}

The algorithm finds the optimum for the battery operational schedule under the assumption that a consumer's electricity bill is only composed of the price of electrical units and there is a single price for units of exported solar energy. For validation, we also formulate the optimization as a MILP problem and solve it using the Pyomo framework [37]. Pyomo provides a fully opensource python-based environment for formulating and analyzing optimization models, with similar functionality to many algebraic modeling languages like AIMS and GAMS. It can be used with many different solvers and here we utilize the CPLEX solver, which is also freely available for academic use. The same objective function specified in Equation 5 is minimized and the optimization is constrained by adapting the constraints from Equations 6, 7, 8, 9, 10, 11 and 12.

Simulating a number of test cases we find that the developed algorithm returns the same optimum as the MILP formulation. In general, the developed algorithm written in python achieves the result four to ten times faster than the MILP formulation when tested with a year of demand, generation and electricity prices. For comparison, scheduling the battery for maximum selfconsumption with a year's worth of demand is around two orders of magnitude faster than the MILP formulation. To aid with reproducibility, our code which runs the test cases for all three scheduling methods is available at https://github.com/EdwardBarbour/ schedule_batt.

\subsection{Modeled PV and battery costs}

It is assumed that each PV installation costs $\$ 3,500$ per $\mathrm{kW}$ installed and has a lifetime of 30 years, and that each consumer benefits from the full value of the investment tax credit, which reduces the effective cost further by $30 \%$. Maintenance costs for PV systems are assumed at $\$ 10 / \mathrm{kW} /$ year [38] and the installed solar capacity is estimated by assuming that the maximum observed 15 minute power for each prosumer corresponds to $95 \%$ of their installed capacity - i.e. a peak power of $4750 \mathrm{~kW}$ would imply a $5 \mathrm{~kW}$ installation.

We consider that battery costs are composed of cell costs and inverter costs. We assume that lithium ion cells cost $\$ 250 / \mathrm{kWh}$ and that the inverter is sized to match the maximum rated charging/discharging capacity of the battery $(0.5 \mathrm{C})$. We assume inverter costs of
$\$ 1500$ for a $3 \mathrm{~kW}$ inverter ${ }^{5}$ and that these scale to the power of 0.7 after $3 \mathrm{~kW}$ so there is some economy of scale. The inverter cost was modeled after recommendations given by various inverter manufacturers and similar inverter costs were used in [18]. Therefore, the total capital cost $\left(\mathrm{Cap}^{\text {batt }}\right)$ of a battery of capacity $x$ $\mathrm{kWh}$ is expressed by Equation 18.

$$
\mathrm{Cap}^{\text {batt }}=250 x+1500\left(\frac{0.5 x}{3}\right)^{0.7}
$$

This yields a total cost of $\$ 6,215$ for a $14 \mathrm{kWh}$ battery, which can be compared to the quoted value of $\$ 5,500$ plus $\$ 700$ supporting hardware for the Tesla Powerwall 2.0 which includes an inverter ${ }^{6}$.

\subsection{Calculating a consumers economic benefits}

The annual saving from a PV installation or a battery for consumer $i$ are expressed by Equations 19 and 20 respectively.

$$
\begin{gathered}
B_{i}^{P V}=\sum_{i=0}^{t=N} d_{i}(t) \pi(t)-\chi_{i}^{P V} \\
B_{i}^{B}=\chi_{i}^{P V}-\chi_{i}^{P V B}
\end{gathered}
$$

Here $\chi_{i}^{P V}$ and $\chi_{i}^{P V B}$ are consumer $i$ 's total yearly electricity bill when they have a PV installation or a PV-battery installation respectively. $\chi_{i}^{P V}=\sum_{t=0}^{t=N} c_{i}(t)$, where $c_{i}(t)$ is obtained from Equation 2 or Equations 3 and 4 for NEM or FIT policies respectively and $E S_{i}(t)=$ 0 for all times. $\chi_{i}^{P V B}$ is equal to the minimum cost calculated by Equation 5 .

The net total benefit of either a solar installation or battery is only positive if the total benefits over the course of the system lifetime outweighs the costs. Therefore, the economic benefit is expressed in terms of the Net Present Value (NPV), the cumulative benefit of a system over its projected lifetime, accounting for the time value of capital. Each yearly net cash flow, $C F(y)$, is the sum of the yearly benefits and costs as expressed in Equations 21, 22, 23, 24.

$$
\begin{aligned}
& \text { IF } y==0 \\
& C F_{i}^{P V}(y)=-C_{a} p_{i}^{P V} \\
& C F_{i}^{B}(y)=-C a p_{i}^{B} \\
& \operatorname{ELSE~IF~} y \geq 1 \\
& C F_{i}^{P V}(y)=B_{i}^{P V}\left(r^{\text {inf }}\right)^{y}-O M\left(r^{\text {inf }}\right)^{y} \\
& C F_{i}^{B}(y)=B_{i}^{B}\left(r^{\text {inf }}\right)^{y}
\end{aligned}
$$

\footnotetext{
${ }^{5}$ https://www.sma.de/en/products/battery-inverters.html

${ }^{6}$ https://www.tesla.com/powerwall
} 
$O M$ is the operation and maintenance costs of the PV system and we assume that both the yearly benefit and yearly costs inflate at a rate of $r^{i n f}=2 \%$, which we base on the average increase in US residential electricity prices over the last decade of $2 \%$ [39]. To calculate NPV each yearly net cash flow is discounted by the discount rate, $r^{d}=5 \%$. The discount rate can be considered as the average cost of tying up capital. The lifetime of PV systems is assumed as 30 years and the battery lifetime is calculated by extrapolating the consumers yearly equivalent full cycles, assuming that each battery installation has a lifetime of 3000 equivalent full cycles. The discounted yearly costs of the system can be summed over the lifetime to obtain the Net Present Value (NPV), as shown in Equation 25.

$$
N P V=\sum_{y=0}^{y=L i} \frac{C F(y)}{\left(1+r^{d}\right)^{y}}
$$

NPV can then be used to assess whether the PV system or battery makes financial sense or not, with a positive NPV implying that the project will make a net gain over its lifetime and a negative NPV implying it represents a poor investment in a financial sense.

While we simulate consumers using their batteries for energy time-shifting to minimize the cost of their electricity, it should be noted that there are many other possible uses for storage. These include energy management, peak shaving, voltage stability, providing ancillary services or deferring transmission/distribution infrastructure upgrades [40].

\section{Results}

\subsection{Storage for self-sufficiency}

As illustrated in section 2.1, PV generation only meets $35 \%$ of the demand of a diverse set of prosumers over the year (see Figure 2). This is a core motivating factor for battery adoption [21], and we first investigate how much battery capacity is needed to reach various levels of self-sufficiency for all the consumers. To do this, we schedule the batteries for maximum selfsufficiency (as described in Equations 14-17) and increment the battery capacity for each consumer until their yearly self-sufficiency with a battery is raised above a desired threshold. This leads to the distributions of required battery capacity for different levels of selfsufficiency as shown in Figure 3.

We find that the practical limit of self-sufficiency for most consumers is below $75 \%$ with a battery capacity below $20 \mathrm{kWh}-$ Figure $3 \mathrm{~d}$ shows that $54 \%$ of consumers reach the $70 \%$ self-sufficiency threshold with a battery smaller than $20 \mathrm{kWh}$, whereas only $26 \%$ reach the $75 \%$ self-sufficiency threshold. On average, we find that the first kWh of battery capacity can increase a consumers self-sufficiency by $3.1 \%$, whereas this drops to $1.5 \%$ by the tenth $\mathrm{kWh}$ of battery capacity and we find that the average increase in self-sufficiency from a 10 $\mathrm{kWh}$ battery is $23.8 \%$ (see Figure $3 \mathrm{~d}$ ). This is favorably compared to studies which have estimated that demand side management without storage can increase a consumers self-sufficiency by only a few percentage points $[41,42]$. When normalized per MWh of yearly PV generation, we see that in general there is very little additional self-sufficiency benefit available by increasing battery capacities past $3 \mathrm{kWh}$ per MWh of yearly solar generation. [30] found the equivalent value for Swedish households was $4 \mathrm{kWh} / \mathrm{MWh}$.

\subsection{Economics of residential $P V$ and batteries}

We now investigate the NPV of PV systems and batteries for all the consumers under both FIT and NEM based policies, for several representative tariffs from the different consumer regions. We select two tariffs from the local utility in Austin (Austin Energy), two tariffs available in San Diego (from San Diego Gas and Electric and PG\&E) and one from Boulder (XCEL energy), all with differing price levels and structures. We also add two hypothetical tariffs corresponding to the Day Ahead market prices for Austin which we assume is net metered, denoted ERCOT DA prices, and the CA flat FIT, which uses the regular PG\&E flat rate but assumes that solar is rewarded using the California FIT. Each consumer is assigned a battery which has the potential to increase their self-sufficiency to $55 \%$, which gives a median battery capacity of approximately $8 \mathrm{kWh}$ (which is within the size range of residential batteries currently available). However, the batteries are optimized to minimize electricity bills rather than for selfsufficiency. The electricity tariffs and the results for the NPV of both batteries and PV systems are shown in Table 1 .

It is clear that the prices available in California are the most favorable for PV systems, with the largest return on investment occurring with the SDGE TOU tariff. This is due to the incredibly high prices during the summer peak period, which occur during hours of high solar production, and the NEM structure which means that exported solar is also valued at this level. The flat rate NEM PG\&E tariff offers the next highest profitability for PV-only, higher than the CA flat FIT with the same retail price level, as the reward for exported solar is much higher under the NEM policy (each $\mathrm{kWh}$ of exported solar is rewarded at $\$ 0.286 / \mathrm{kWh}$ compared to 

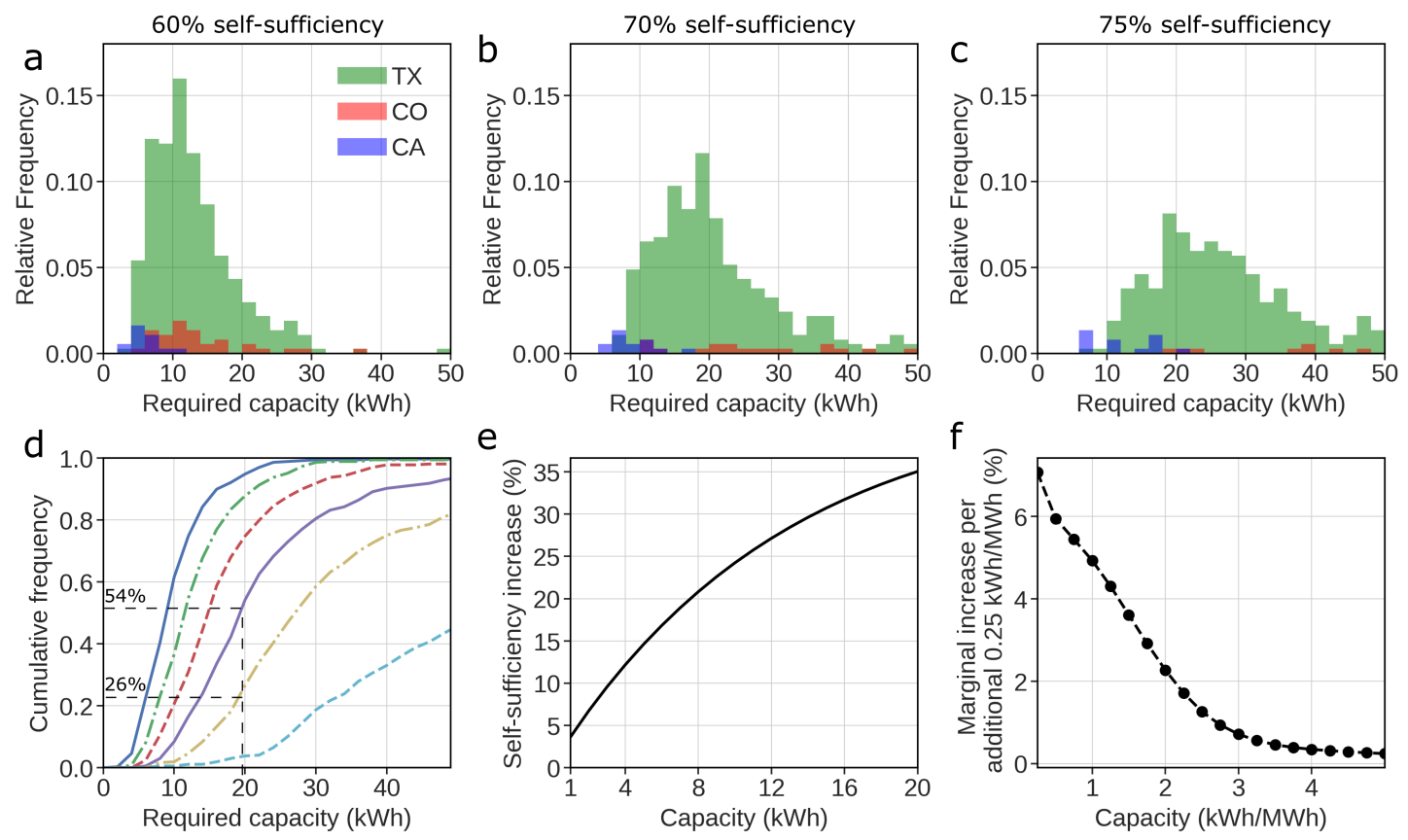

f

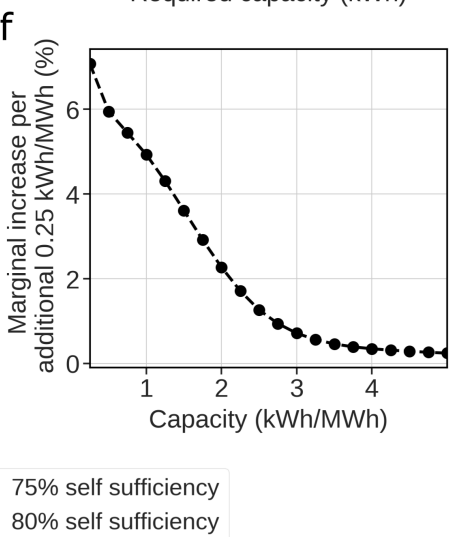

Figure 3: Batteries for self-sufficiency. (a) Distribution of the battery capacities required for $60 \%$ self-sufficiency. (b) Battery capacities for $70 \%$ self-sufficiency. (c) Battery capacities for $75 \%$ self-sufficiency. The distribution is colored the region. (d) Cumulative distribution of required battery capacity for all consumers for different self-sufficiency thresholds. (e) Average increase in self-sufficiency against battery size for all consumers. (f) Average increase in self-sufficiency per additional $0.25 \mathrm{kWh}$ of battery storage per MWh of generation for all consumers.

$\$ 0.10 / \mathrm{kWh}$ ). With the Austin-based tariffs (Austin Energy TOU and Austin Energy flat), the NPV of PV-only systems for the average consumer is just above zero, indicating that most consumers just manage to recover the costs of their solar panel over its lifetime. Most consumers do not recover the cost of their PV installation with either the Xcel Energy tariff or the wholesale ERCOT prices. With regard to the consumer regions, it is also clear that California consumers generally have higher returns under all tariffs per $k W$ of installed PV, due to the better solar resource in San Diego compared to the other locations (the average Global Horizontal Irradiance in San Diego is $5.26 \mathrm{kWh} / \mathrm{m} 2 /$ day compared to $4.74 \mathrm{kWh} / \mathrm{m} 2 /$ day in Austin and $4.41 \mathrm{kWh} / \mathrm{m} 2 /$ day in Boulder [43]). Therefore even though these consumers have smaller demands (see Figure 2) they produce more PV per $\mathrm{kW}$ installed, and thus per unit investment.

The NPV of batteries is negative for all consumers in all regions, indicating that they always represent a loss when considered from an investment perspective. This is also true when consumers are exposed to the highly variable ERCOT day-ahead prices. In this case, even though there are significant opportunities for storage to displace electricity consumption at times of relatively higher prices with electricity from lower price periods, the absolute level of the prices remain too low for batteries to be a worthwhile investment. The hypothetical case of the CA flat FIT offers the highest battery NPV, however the median value is $\$-90 / \mathrm{kWh}$. This can be compared to the present cost of $\$ 480 / \mathrm{kWh}$ for a $8 \mathrm{kWh}$ battery, so the battery is only able to recover $\frac{480-90}{480}=81 \%$ of the initial investment. Therefore, it is clear that if batteries are to experience a boom in residential deployment electricity prices will have to increase significantly, battery costs will have to decline very significantly or other value propositions will become more important, i.e. to reduce peak demand or for reliability.

Figure 4 shows the distribution of NPVs for the SDGE TOU tariff (Figures $4 \mathrm{a}$ and $4 \mathrm{~b}$ ) and the CA flat FIT (Figures $4 \mathrm{c}$ and $4 \mathrm{~d}$ ) for both PV and batteries. As previously noted, PV systems in San Diego produce a larger amount of energy per $\mathrm{kW}$ installed and therefore the NPV of PV is highest for the San Diego consumers. 
Table 1: NPV of PV and batteries in representative tariffs. For each tariff the number outside the parenthesis is the median Net Present Value (NPV) for the consumers in the tariff region while the number in parenthesis is the median for all the consumers.

\begin{tabular}{|c|c|c|c|c|}
\hline Name & Electricity cost $(\times \$ 0.01 / \mathrm{kWh})$ & $\begin{array}{c}\text { Solar Reward } \\
(\times \$ 0.01 / \mathrm{kWh})\end{array}$ & $\begin{array}{c}\text { PV Net present } \\
\text { value }(\$ / \mathrm{kW})\end{array}$ & $\begin{array}{c}\text { Batt. Net present } \\
\text { value }(\$ / \mathrm{kWh})\end{array}$ \\
\hline $\begin{array}{c}\text { Austin } \\
\text { Energy flat }^{1}\end{array}$ & $\begin{array}{c}\text { Flat Rate Summer: } 9.1 \\
\text { Flat Rate Winter: } 7.2\end{array}$ & 10.9 & $84(77)$ & $-479(-479)$ \\
\hline $\begin{array}{c}\text { Austin } \\
\text { Energy TOU }\end{array}$ & $\begin{array}{c}\text { Summer } 2 \mathrm{pm}-8 \mathrm{pm}: 12.2 \text {, } \\
\text { 8pm-10pm, 6am-2pm, weekends } \\
\text { 6am-10pm: } 7.2 \\
\text { 10pm-6am: } 2.2 \text {. } \\
\text { Winter 6am-10pm: } 7.1,10 \mathrm{pm}-6 \mathrm{am}: \\
2.2 .\end{array}$ & 10.9 & $54(50)$ & $-333(-335)$ \\
\hline $\begin{array}{c}\text { ERCOT DA } \\
\text { prices }^{2} \\
\end{array}$ & min: 0.5, max: 225.0, mean: 2.7 & NEM & $-1,596(-1,601)$ & $-440(-441)$ \\
\hline $\begin{array}{c}\text { San Diego } \\
\text { Gas Electric } \\
\text { TOU }^{3}\end{array}$ & $\begin{array}{c}\text { Summer 11am-6pm: 50.6, } \\
\text { 6pm-10pm, 6am-11am: 25.1, } \\
\text { 10pm-6am, weekends: } 23.7 \\
\text { Winter 6am-6pm: 23.6 } \\
\text { 6pm-6am, weekends: 22.2. }\end{array}$ & NEM & $8,242(6,024)$ & $-389(-314)$ \\
\hline $\begin{array}{l}\text { PG\&E flat } \\
\text { NEM }^{4}\end{array}$ & Flat Rate: 28.6 & NEM & $7,884(5,128)$ & $-532(-479)$ \\
\hline CA flat FIT & Flat Rate: 28.6 & 10 & $3,572(1,953)$ & $-143(-90)$ \\
\hline $\begin{array}{c}\text { XCEL } \\
\text { Energy TOU }\end{array}$ & $\begin{array}{c}\text { Summer 2pm-6pm: 13.8, } \\
\text { 9am-2pm, 6pm-9pm, weekends } \\
\text { 9am-9pm: 8.4, 9pm-9am: 4.4. } \\
\text { Winter 2pm-6pm: 8.9, } \\
\text { 9am-2pm, 6pm-9pm, weekends } \\
\text { 9am-9pm: 5.4, 9pm-9am: 4.4. }\end{array}$ & NEM & $-825(-488)$ & $-421(-404)$ \\
\hline
\end{tabular}

\footnotetext{
${ }^{1}$ http://austinenergy.com/

2 http://www.ercot.com/mktinfo/prices

${ }^{3}$ https://www.sdge.com/rates-regulations/current-and-effective-tariffs/electric-tariff-book-residential-rates

${ }^{4}$ https://www.pge.com/tariffs/electric.shtml\#RESELEC

${ }^{5}$ https://www.xcelenergy.com/staticfiles/xe/PDF/Regulatory/CO-Rates-\&-Regulations-Entire-Electric-Book.pdf
}

NPVs of PV systems under the CA flat FIT tariff are also higher for consumers with higher self-sufficiency. For batteries, under the SDGE TOU tariff, there is a trend for consumer's with higher levels of initial selfsufficiency to have a higher battery value whereas there is the opposite trend under the CA flat FIT tariff. This is important as the CA flat FIT encourages consumers with low self-sufficiency to adopt batteries, whereas the SDGE TOU tariff does not. The battery NPVs are also affected by region, with consumers in San Diego having a lower value. This is due to the fact that these consumers generally have smaller demands and therefore require smaller batteries to reach $55 \%$ self-sufficiency, and in our model battery costs benefit from an economy of scale, with larger systems having lower inverter costs.
We see also see that under the CA flat FIT consumers in Boulder have relatively higher battery value. this is explained as the self-sufficiency of these consumers without battery is generally lower, due to the highly seasonal nature of their solar resource (see Figure 2).

\subsection{Projecting a future boom for PV-battery systems}

The results of the previous sections 3.1 and 3.2 illustrate that while moderate battery sizes can significantly increase the self-sufficiency of residential consumers, economically batteries are a poor investment. Previous works have investigated at what point batteries become profitable investments, typically using current tariffs and reducing the costs of batteries until profitability is reached i.e. [23, 18, 24, 44], and some works have 

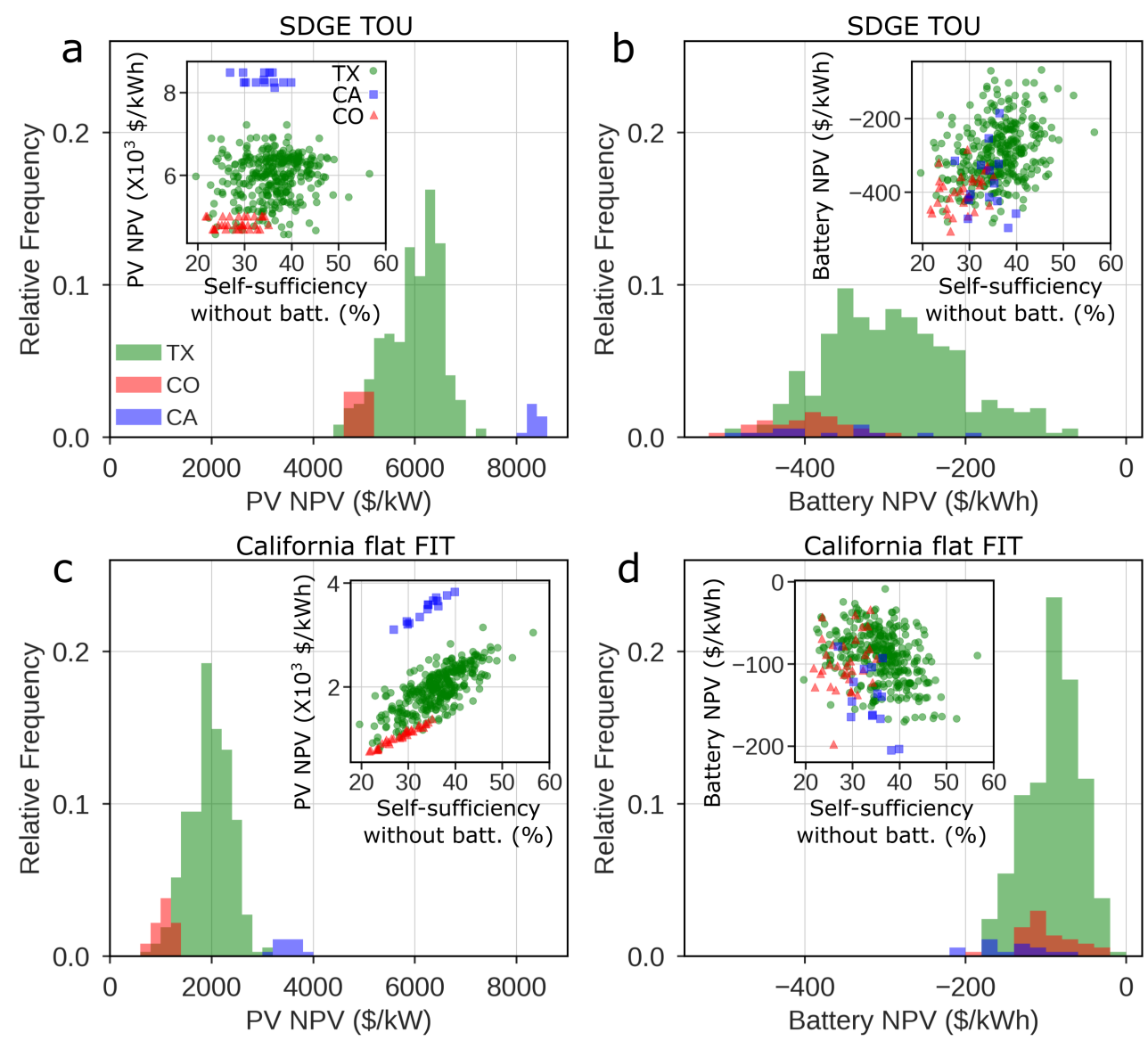

Figure 4: PV and battery NPVs. (a) The distribution of PV NPVs for all consumers with the SDGE TOU tariff. (b) The distribution of battery NPVs with the SDGE TOU tariff. (c) The distribution of PV NPVs with the CA flat FIT. (b) The distribution of battery NPVs with the CA flat FIT. Consumers are colored by region and the insets in each subplot show the NPV against consumer self-sufficiency without battery.

investigated tariffs intended to be representative of future scenarios $[18,27]$. Here we systematically evaluate the potential for a boom in battery deployment, which is likely to occur when the payback of coupled PV-battery systems is faster than the payback of standalone PV systems for the majority of consumers. We consider a FIT tariff structure as this is the most widely adopted mechanism for rewarding residential solar systems and is a suitable structure for battery adoption [45]. Therefore, we assume a flat rate for residential electricity prices and assume surplus solar electricity is rewarded by a fixed FIT. Each consumer's battery is operated to maximize their self-sufficiency. We consider electricity prices between $\$ 0.10 / \mathrm{kWh}$ and $\$ 0.60 / \mathrm{kWh}$ and FITs between zero and $\$ 0.25 / \mathrm{kWh}$. At each price point we estimate the discounted payback (i.e. the time taken to recover the initial investment over which the NPV is zero) for each consumer with a PV-system and a cou- pled PV-battery system, using the same battery capacity as the previous section (the size required for $55 \%$ selfsufficiency). We then compare the difference between the median discounted payback for standalone solar PV systems to the median payback for PV-battery systems at each price point.

In Figures 5 and 6, we add points to illustrate the approximate position of the average residential electricity prices and FIT export tariffs for the years 2012 and 2015 in different regions with high solar adoption (see Appendix B). It must be noted that the solar resources and demand patterns in these countries will be significantly different to our modeled consumers, however indicating prices for these regions is nonetheless considered to add useful context. The prices in several regions (UK, Spain, Italy and the UK) in 2012 fall outside the region of interest due to their high FIT rates, which mean that batteries will not be close to profitability. Shifts in FIT 

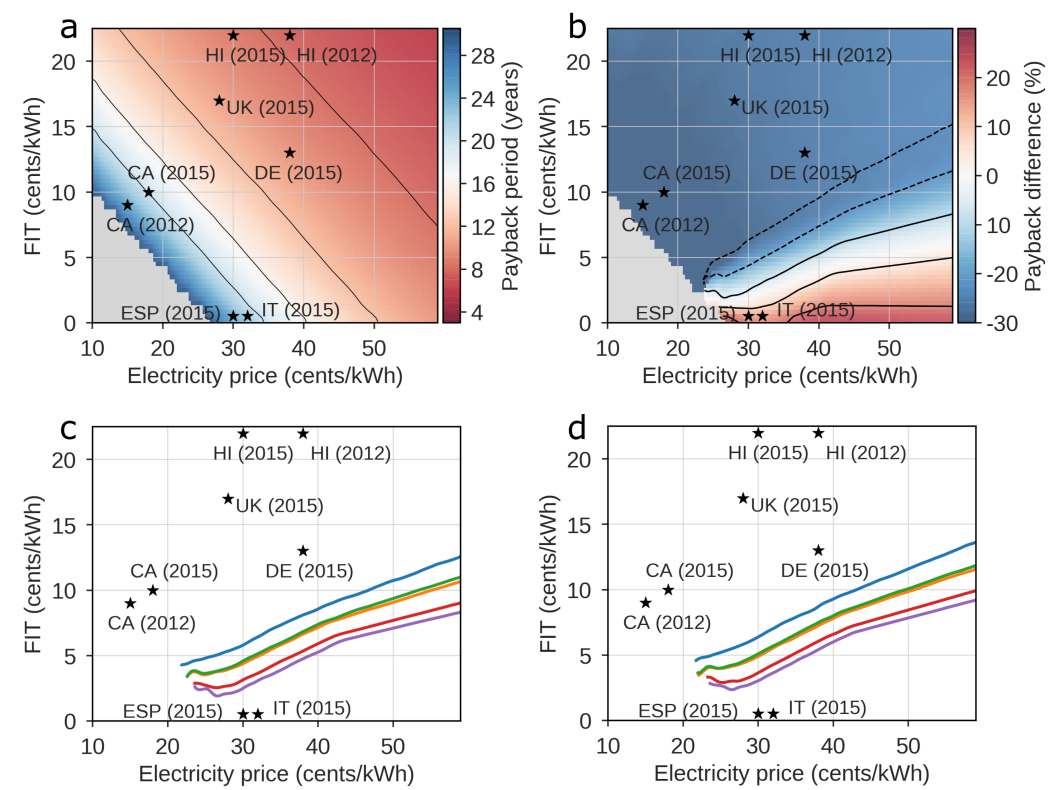

cell costs: $\$ 100 / \mathrm{kWh}$, Inverter costs: $\$ 750 / 3 \mathrm{~kW}$ _ cell costs: $\$ 100 / \mathrm{kWh}$, Inverter costs: $\$ 1500 / 3 \mathrm{~kW}$

cell costs: $\$ 200 / \mathrm{kWh}$, Inverter costs: $\$ 1500 / 3 \mathrm{~kW}$ cell costs: $\$ 200 / \mathrm{kWh}$, Inverter costs: $\$ 750 / 3 \mathrm{~kW}$

cell costs: $\$ 250 / \mathrm{kWh}$, Inverter costs: $\$ 1500 / 3 \mathrm{~kW}$

Figure 5: When are PV-battery systems a better investment than PV-only systems? (a) Heat map showing the median discounted payback for standalone PV systems (in years) at current PV prices. (b) Heat map showing the difference between the median payback period of PV-only and PV-battery systems (\%) at current PV and battery prices. (c) Illustrating the movement of the zero contour line - i.e. the point at which PV-battery systems and PV-only systems are equally profitable - at different battery costs. (d) Illustrating the movement of the zero contour line when battery efficiency is increased to $97 \%$. Points corresponding to the approximate price points in different regions are illustrated. The gray area illustrates where no payback is achieved within the system lifetime.
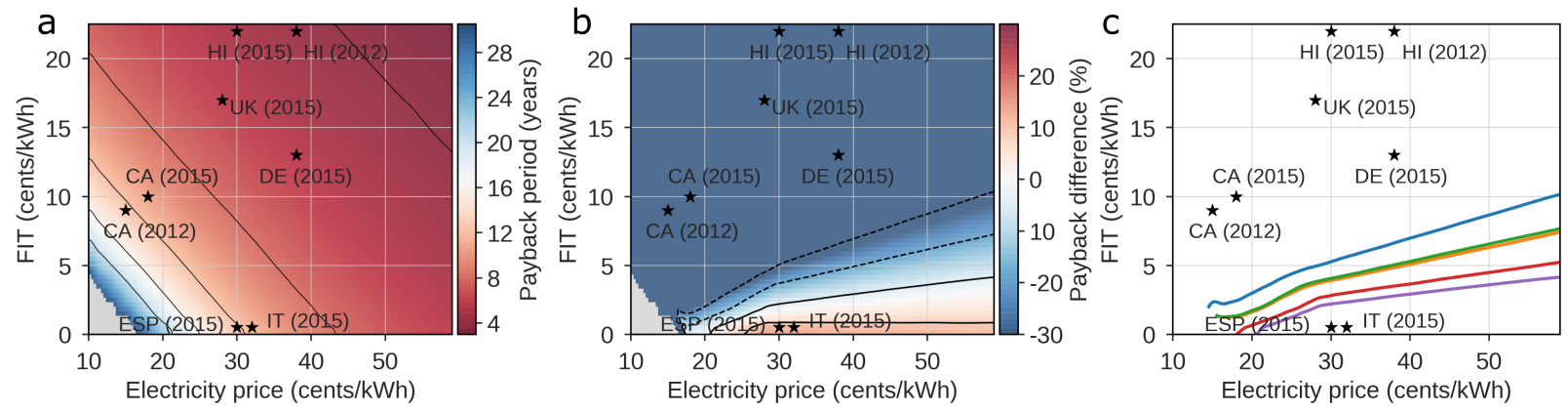

\footnotetext{
cell costs: $\$ 100 / \mathrm{kWh}$, Inverter costs: $\$ 750 / 3 \mathrm{~kW}$ cell costs: $\$ 200 / \mathrm{kWh}$, Inverter costs: $\$ 750 / 3 \mathrm{~kW}$
} cell costs: $\$ 200 / \mathrm{kWh}$, Inverter costs: $\$ 1500 / 3 \mathrm{~kW}$
cell costs: $\$ 250 / \mathrm{kWh}$, Inverter costs: $\$ 1500 / 3 \mathrm{~kW}$

Figure 6: What is the effect of declining PV prices? (a) Heat map showing the median discounted payback for standalone PV systems (in years) with a $40 \%$ reduction in PV costs. (b) Heat map showing the difference between the median payback period of PV-only and PV-battery systems at with $40 \%$ reduction in PV costs (\%) and current battery prices. (c) Illustrating the movement of the zero contour line at different battery costs.

policy between 2012 and 2015 have been particularly dramatic in Spain (ESP) and Italy (IT), where FITs have been suspended and are effectively zero. In Germany (DE) and the UK, the decline of the FIT rate has been more gradual. All of the plotted regions have seen an increase in the average retail electricity prices between 2012 and 2015, except for Hawaii (HI), whose primary energy supply is heavily dependent on petroleum. 
We observe that with current modeled battery and PV costs, PV-battery systems offer faster return on investment than PV-only systems at electricity price levels similar to those observed in Spain and Italy in 2015 (see Figure 5a and 5b). However, here the payback for PV-only systems is in excess of 20 years due to the lack of policy support. German electricity prices are the next closest to profitability for PV-battery systems, however even at the lowest battery costs that we model $(\$ 100 / \mathrm{kWh}$ cell costs and $\$ 750 / 3 \mathrm{~kW}$ inverter, resulting in a total cost of $\$ 2,800$ for a $14 \mathrm{kWh}$ battery), PV-battery systems are still less economic for the majority of consumers than PV-only systems (see Figure 5c). We also investigate the effect of increasing battery efficiency and Figure $5 \mathrm{~d}$ shows the case when battery round trip efficiency is increased from $85 \%$ to $97 \%$. Despite this relatively large increase in efficiency, the effect on extending the region where PV-battery systems are more economic is limited, especially at low prices. This is due to the low increase of the value of electricity in the battery and the fact that consumers often have more surplus electricity than required to fill their battery. For example, with an electricity price of $\$ 0.40 / \mathrm{kWh}$ and a FIT of $\$ 0.05 / \mathrm{kWh}$, the cost of charging the $85 \%$ and $97 \%$ efficient batteries is $\frac{0.05}{\sqrt{0.85}} \$ / \mathrm{kWh}$ and $\frac{0.05}{\sqrt{0.97}} \$ / \mathrm{kWh}$ respectively, while the reward from discharging is $0.40 \sqrt{0.85}$ $\$ / \mathrm{kWh}$ and $0.40 \sqrt{0.97} \$ / \mathrm{kWh}$ respectively, and therefore the additional earning of the $97 \%$ efficient battery is only $\$ 0.03$ per $\mathrm{kWh}$ discharged.

Conversely, further decreases in PV costs have a large negative effect on the relative benefits of PV-battery systems, shrinking the region in which PV-battery systems are more economic very significantly. Figures $6 a-6 c$ illustrate how the results change for a $40 \%$ reduction in installed PV costs (from $\$ 3,500 / \mathrm{kW}$ to $\$ 2,100 / \mathrm{kW}$ ). As a result of this analysis, it is suggested that if coupled PV-battery systems are to become widely adopted, electricity prices above $\$ 0.40 / \mathrm{kWh}$ and FIT rates of $\$ 0.05 / \mathrm{kWh}$ or below will be necessary. This is primarily due to further expected declines in PV installation costs and the lower sensitivity of PV-battery profitability to battery price decreases or efficiency increases. We anticipate that batteries will certainly remain uneconomic for the majority of consumers if electricity prices stay below $\$ 0.30 / \mathrm{kWh}$ or FITs are above $\$ 0.10 / \mathrm{kWh}$.

\section{Discussion}

Combining residential PV installations with batteries is gaining significant attention as electricity prices rise and cheaper battery technologies appear on the market.
Consumers have favorable battery opinions and are motivated by the idea of self-sufficiency (less reliance on the utility) and saving on their electricity bills [21]. In terms of self-sufficiency, we find that moderate battery sizes (within the range of currently available capacities) can make a very significant contribution to a consumers self-sufficiency, although the self-sufficiency limit for most consumers is between $70 \%$ and $75 \%$ with a battery smaller than $20 \mathrm{kWh}$. For further self-sufficiency gains above this level, the increase in required battery size becomes impractically large for most consumers without oversizing their PV system, which is unlikely to be a widespread solution in high adoption areas. In economic terms, for the available tariffs that we explicitly studied in the consumer regions, none made economic sense for batteries. This was because either the FIT reward for solar export was too high or the price differentials in the net metered tariffs were insufficient to make battery load-shifting profitable. Studying distributions of the net present value of PV systems, it was interesting to note how existing NEM based tariffs actually discouraged consumers with low self-sufficiency to adopt batteries. FIT based tariffs with low export rates rewarded consumers with low self-sufficiency for adopting batteries, however these rewards were insufficient for battery payback.

Studying the sensitivity of PV and battery economics to a range of electricity prices and FIT rates, our analysis suggests that batteries will not experience widespread adoption unless electricity prices increase above $\$ 0.40 / \mathrm{kWh}$ and rewards for exported solar generation fall below $\$ 0.05 / \mathrm{kWh}$. For the current tariffs that we explicitly studied, all either had electricity prices below this price threshold or rewards for solar which were above the FIT threshold. However, looking outside of our immediate consumer locations, electricity prices in other international areas do fall within the region where combined PV-battery systems may be economic. This is also set within the context of the current international trends of increasing residential electricity prices and decreasing solar rewards [46, 47]. Therefore, it is possible that a combination of these factors could lead to a residential solar-storage boom. Additionally, battery costs are rapidly declining [47] and will increase the reach of this region to lower electricity prices and higher solar reward levels, however we find that without very large increases in retail electricity prices this effect is limited. We also find that increasing battery efficiency has a relatively small impact on the price levels at which PV-battery systems become more economic, underlining that battery costs rather than efficiency are a larger barrier to adoption. 
Importantly, we find that reductions in the installed cost of PV may dissuade consumers from battery adoption, as declining PV costs decrease the relative benefit available from batteries. Furthermore, in this study we assumed PV systems sized to match the consumers demand, and therefore smaller PV systems may offer faster returns due to less surplus electricity. However, given that self-sufficiency is a motivating factor for storage and currently PV systems are often sized to produce similar amounts of electricity to a consumers total demand, this is nonetheless a useful comparison.

In regions where electricity prices remain below $\$ 0.30 / \mathrm{kWh}$ or rewards for exported solar generation are above $\$ 0.10 / \mathrm{kWh}$, battery adoption will remain limited even with huge declines in cell costs, unless driven by other electricity charges like those related to peak demand reduction. However, where PV is widely profitable, concerns about over-prevalence may lead to significant tariff changes. This is particularly relevant for NEM tariffs which are being phased out and reformulations proposed [48]. Therefore, future techno-economic studies on battery adoption should consider novel tariff structures, in particular those with high penalties $(\$ / \mathrm{kW})$ for high demand at peak times. Here, it may also be the case that technical battery characteristics (for example degradation, lifetime, efficiency, self-discharge and Crate) are more important.

There is no doubt that residential batteries have the potential to disrupt typical utility operations [49], and importantly they also represent significant cost and embodied energy [50]. Therefore, understanding the point at which they are likely to become widely adopted is crucial to understand for the electricity industry and policy makers alike, and data-informed studies like the one presented help in this regard.

\section{Conclusion}

This paper has used a data-driven approach to understand residential battery adoption. While our results show that the current generation of residential batteries can make large contributions to consumer selfsufficiency, they remain too expensive to be a good economic choice for residential PV prosumers. Furthermore, many currently available tariffs for residential consumers are unsuited for battery adoption and do not encourage consumers who have low self-sufficiency from their PV systems to adopt batteries. Exceptions to this are tariffs with high retail prices and low rewards for exported solar generation.

In terms of a PV-battery boom, there are many factors to consider. These include electricity prices, bat- tery costs and performance, PV self-consumption, and demand charges, as well as consumer preferences for self-sufficiency and reliability. Our work suggests that widespread battery adoption driven by electricity prices or PV self-consumption will not occur unless retail electricity prices rise beyond $\$ 0.40 / \mathrm{kWh}$ with effective solar rewards falling to or below $\$ 0.05 / \mathrm{kWh}$.

\section{Appendix A: Battery scheduling algorithm}

The scheduling algorithm for the energy storage is described in the main text in Section 3. This appendix provides additional accompanying Figures. Figure 7 shows a flowchart outlining the operation of the battery scheduling algorithm.

Figure 8 shows examples of the resulting operational schedules from the algorithm for three different test case days, for a prosumer with surplus PV generation during the daytime hours. For each test case, the electricity price is illustrated, as well as the action of the battery and the resulting net demand.

Figure $8 \mathrm{a}$ shows the battery operational schedule when there is a fixed electricity price and a fixed export (FIT) rate for surplus solar generation, which is lower than the electricity price. As expected, the economically optimum schedule for the battery charges using solar electricity as soon as it exceeds the consumers demand, forfeiting the reward for solar export, defined by the FIT. The battery charges at the minimum of the maximum charging rate or the maximum amount of surplus generation. The battery then discharges stored energy as soon as the consumer's generation no longer meets all of their demand. The battery discharges at the minimum of the maximum discharging rate or the maximum consumer demand minus generation.

Figure $8 \mathrm{~b}$ shows the battery operational schedule when there is a typical Time-Of-Use (TOU) tariff and the consumer is billed on a Net Energy Metered (NEM) basis. The battery charges using low-cost electricity in the early morning period at the maximum charging rate, before discharging as soon as there is consumer demand at the time with the highest electricity price. The battery discharges at the minimum of the maximum discharging rate or the maximum consumer demand minus generation.

Figure 8c illustrates the operational schedule when the consumer is exposed to the day ahead prices. Again the consumer is assumed to be billed under a NEM structure. We see that the algorithm schedules the battery to charge at the lowest price points during the day, discharging the battery during the subsequent peaks in the electricity price. Again the battery discharges he 


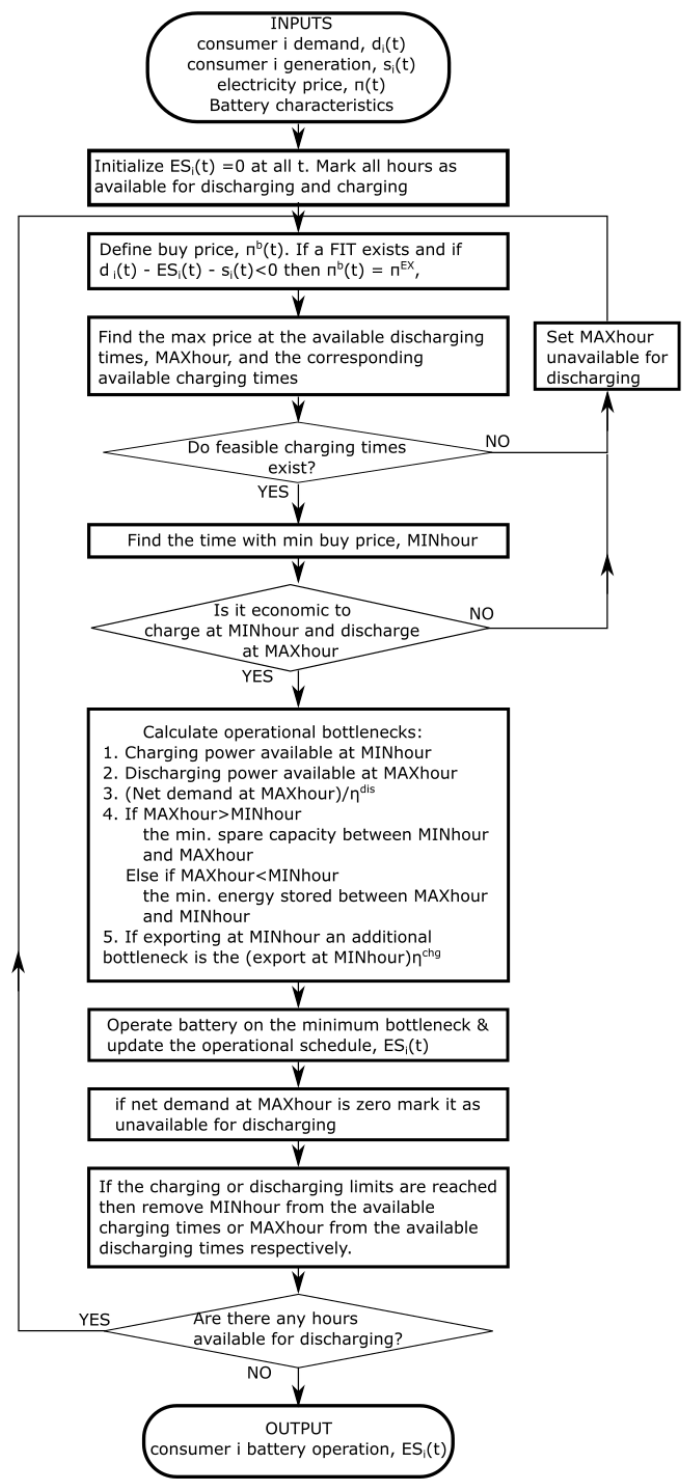

Figure 7: A flowchart outlining the operation of the battery scheduling algorithm.

battery discharges at the minimum of the maximum discharging rate or the maximum consumer demand minus generation.

\section{Appendix B: Typical electricity prices and FIT rates in different high solar regions.}

This appendix details estimates of approximate electricity prices and FIT rates for residential-scale PV installations in several international high-solar regions.

\section{Table Notes}

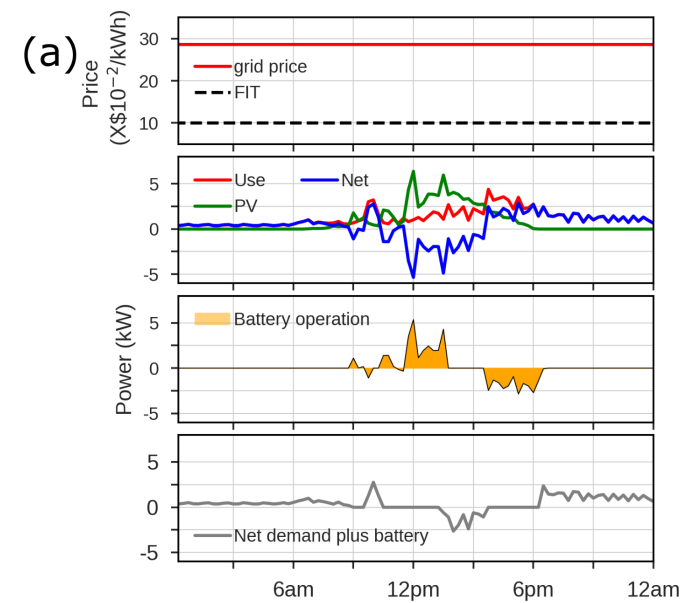

(b)

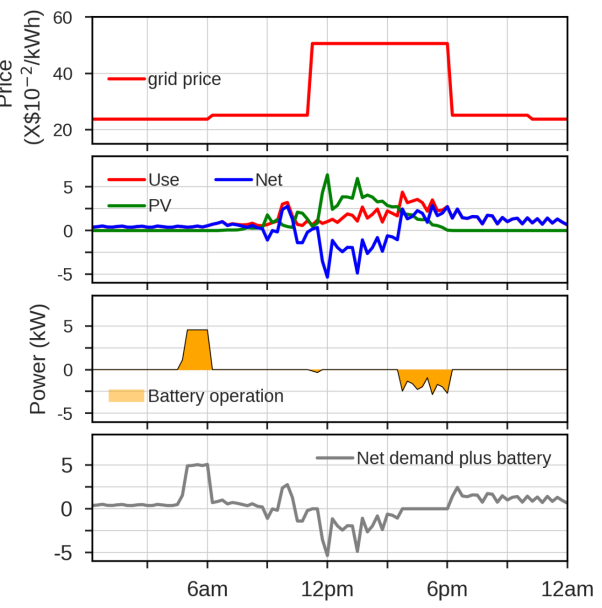

(C)

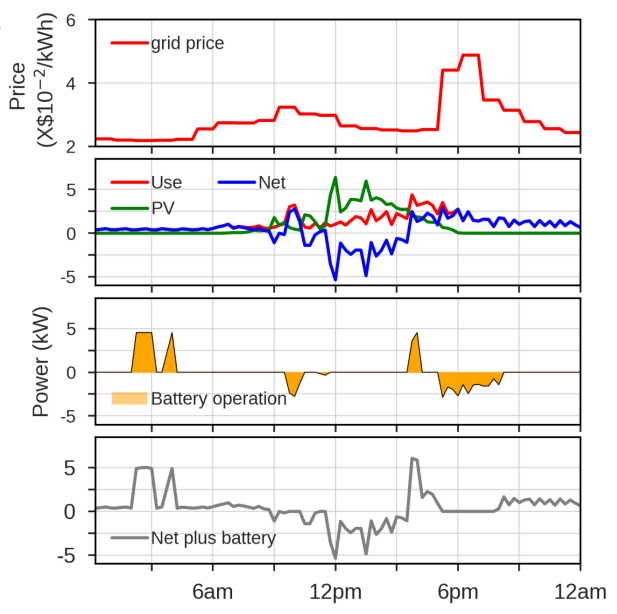

Figure 8: (a) Scheduling results with a flat price and Feed In tariff. (b) Scheduling results with a NEM Time of Use tariff. (d) Scheduling results with day-ahead prices.

${ }^{1}$ In 2009 the solar FIT for rooftop PV systems with less than $20 \mathrm{~kW}$ installed capacity was $€ 0.34$ with a $10 \%$ 
Table 2: Average retail electricity prices and FIT PV export tariffs. All values are in $\$ / \mathrm{kWh}$

\begin{tabular}{|c|c|c|c|c|}
\hline Country & $\begin{array}{c}\text { Retail } \\
2012\end{array}$ & $\begin{array}{c}\text { FIT } \\
2012\end{array}$ & $\begin{array}{c}\text { Retail } \\
2015\end{array}$ & $\begin{array}{c}\text { FIT } \\
2015\end{array}$ \\
\hline Spain $^{1}$ & 0.27 & 0.32 & 0.30 & - \\
Germany $^{2}$ & 0.33 & 0.25 & 0.38 & 0.13 \\
Italy $^{3}$ & 0.29 & 0.32 & 0.32 & - \\
UK $^{4}$ & 0.24 & 0.27 & 0.28 & 0.17 \\
California $^{5}$ & 0.15 & 0.09 & 0.18 & 0.10 \\
Hawaii $^{6}$ & 0.38 & 0.22 & 0.30 & 0.22 \\
\hline
\end{tabular}

reduction rate per year. In 2012 the government suspended the program due to an unsustainable increase in the cost of the solar FIT program. There are several reasons for this including an over-generous FIT program for utility ground-mounted solar PV systems beginning in 2007 and a significant lag in the government's response to falling PV costs [51]. There have also been widespread allegations of corruption.

2 The German Renewable Energy Sources Act (EEG) controls Feed In Tariff rates for Germany. Reduction rate is flexible depending on previous installed capacities and targets [52]. In Germany the FIT is a reward for exported electricity, however there was also a selfconsumption bonus until 2012 (0.22 Euro/kWh in 2010) paid to consumers for consuming their own generation.

${ }^{3}$ At the end of 2011, the Fourth Energy Bill dramatically reduced the FITs for solar PV to $€ 0.25$, which had been as high as $€ 0.38$ at the start of 2011. In 2013 the FIT program was suspended after an increase in PV deployment of more than $15 \mathrm{GW}$ since 2006 [51].

${ }^{4}$ We use the UK rate for systems in the range 4$10 \mathrm{~kW}$. In the UK the FIT is a payment for all electricity generated by the PV system, regardless of whether it is consumed or exported. Surplus exported electricity gains an additional export bonus of $0.05 \mathrm{GBP} / \mathrm{kWh}$.

${ }^{5}$ Most small residential solar systems in California connects under NEM arrangements due to the higher rate of remuneration. However California also has a FIT option for projects up to $1.5 \mathrm{MW}$. The California FIT is based on the avoided costs of generation, rather than the generation costs of renewable technologies, and as a result the generation tariff is significantly lower than most other FITs and has stimulated little development [53]. The Market Price Referent (MPR) is an estimate of the average cost of generation from the power plant that would otherwise be supplying the load in that area. Each $\mathrm{kWh}$ of generation is then rewarded at a price $M P R \times A_{T O U}$, where $A_{T O U}$ is a time of use adjustment factor which depends on time of day and season. In Ta- ble 2 we simply give the MPR (using the 2011 MPR model).

${ }^{6}$ Hawaii introduced its FIT in 2010, and between 2010 and 2015 both FIT and NEM programs were offered. In 2015 Hawaii Public Utilities Commission filed a ruling to close NEM to new participants.

The websites www.statista.com, http://ec.europa.eu /eurostat/, www.FITariffs.co.uk, and https://www. eia.gov/ were invaluable in helping to compile this information.

To convert all prices to $\$ / \mathrm{kWh}$ we use average exchange rates for the period 2012-2015. This yields $€ 1$ $=\$ 1.27$ and $£ 1=\$ 1.58$.

\section{Acknowledgments}

The research was supported in part by grants from the Center for Complex Engineering Systems, the MIT Energy initiative and the MISTI-Brazil exchange program. The authors thank Alexandre Evsukoff, Pedro Bittencourt and Vinicius Viera for enlightening discussions. We also thank Arda Halu for useful information and help with the data preparation and David Parra for discussions regarding batteries.

\section{References}

[1] Climate Change 2014: Mitigation of Climate Change, 2014.

[2] EPA, Inventory of U.S. Greenhouse Gas Emissions and Sinks: 1990-2014, US Environmental Protection Agency (2016).

[3] U.S. Energy Information Administration, Annual Energy Outlook 2015, Technical Report, 2015.

[4] U.S Energy Information Administration, Today In Energy, 2016.

[5] H. Wirth, Recent facts about photovoltaics in Germany, Technical Report, 2015.

[6] H. J. J. Yu, A prospective economic assessment of residential pv self-consumption with batteries and its systemic effects: the french case in 2030, Energy Policy 113 (2018) 673-687.

[7] P. Denholm, R. M. Margolis, Evaluating the limits of solar photovoltaics (PV) in traditional electric power systems, Energy Policy 35 (2007) 2852-2861.

[8] P. Denholm, M. Hand, Grid flexibility and storage required to achieve very high penetration of variable renewable electricity, Energy Policy 39 (2011) 1817-1830.

[9] R. Tonkoski, D. Turcotte, T. H. M. El-Fouly, Impact of high PV penetration on voltage profiles in residential neighborhoods, IEEE Transactions on Sustainable Energy 3 (2012) 518-527.

[10] J. von Appen, M. Braun, T. Stetz, K. Diwold, D. Geibel, Time in the sun: the challenge of high PV penetration in the German electric grid, IEEE Power \& Energy Magazine 3 (2013) 55-64.

[11] M. Mureddu, G. Caldarelli, A. Chessa, A. Scala, A. Damiano, Green power grids: how energy from renewable sources affects networks and markets, PloS one 10 (2015) e0135312.

[12] P. Denholm, M. Connell, G. Brinkman, J. Jorgenson, Overgeneration from Solar Energy in California : A Field Guide to the Duck Chart, Technical Report, National Renewable Energy laboratory, 2015. 
[13] F. Flores-Espino, Compensation for Distributed Solar : A Survey of Options to Preserve Stakeholder Value, Technical Report September, National Renewable Energy Laboratory, NREL/TP6A20-62371, 2015.

[14] R. Luthander, J. Widén, D. Nilsson, J. Palm, Photovoltaic selfconsumption in buildings: A review, Applied Energy 142 (2015) 80-94.

[15] T. Lang, D. Ammann, B. Girod, Profitability in absence of subsidies: A techno-economic analysis of rooftop photovoltaic selfconsumption in residential and commercial buildings, Renewable Energy 87 (2016) 77-87.

[16] L. M. Beard, J. B. Cardell, I. Dobson, F. Galvan, D. Hawkins, W. Jewell, M. Kezunovic, T. J. Overbye, P. K. Sen, D. J. Tylavsky, Key technical challenges for the electric power industry and climate change, IEEE Transactions on Energy Conversion 25 (2010) 465-473.

[17] W. A. Braff, J. M. Mueller, J. E. Trancik, Value of storage technologies for wind and solar energy, Nature Climate Change 6 (2016) 964-969.

[18] D. Parra, M. K. Patel, Effect of tariffs on the performance and economic benefits of pv-coupled battery systems, Applied Energy 164 (2016) 175-187.

[19] S. Zheng, X. Li, B. Yan, Q. Hu, Y. Xu, X. Xiao, H. Xue, H. Pang, Transition-metal (fe, co, ni) based metal-organic frameworks for electrochemical energy storage, Advanced Energy Materials (2017).

[20] R. Lacko, B. Drobnič, M. Mori, M. Sekavčnik, M. Vidmar, Stand-alone renewable combined heat and power system with hydrogen technologies for household application, Energy 77 (2014) 164-170.

[21] M. Graebig, G. Erdmann, S. Röder, Assessment of residential battery systems (rbs): profitability, perceived value proposition, and potential business models, in: 37th IAEE International Conference, New York City.

[22] A.-L. Klingler, Self-consumption with pv+ battery systems: A market diffusion model considering individual consumer behaviour and preferences, Applied Energy 205 (2017) 15601570 .

[23] A. S. Hassan, L. Cipcigan, N. Jenkins, Optimal battery storage operation for pv systems with tariff incentives, Applied Energy 203 (2017) 422-441.

[24] S. Quoilin, K. Kavvadias, A. Mercier, I. Pappone, A. Zucker, Quantifying self-consumption linked to solar home battery systems: Statistical analysis and economic assessment, Applied Energy 182 (2016) 58-67.

[25] M. Akter, M. Mahmud, A. M. Oo, Comprehensive economic evaluations of a residential building with solar photovoltaic and battery energy storage systems: An australian case study, Energy and Buildings 138 (2017) 332-346.

[26] R. L. Fares, M. E. Webber, The impacts of storing solar energy in the home to reduce reliance on the utility, Nature Energy 2 (2017) 17001.

[27] Z. Ren, G. Grozev, A. Higgins, Modelling impact of pv battery systems on energy consumption and bill savings of australian houses under alternative tariff structures, Renewable Energy 89 (2016) 317-330.

[28] J. López Prol, K. W. Steininger, et al., Photovoltaic selfconsumption regulation in spain: Profitability analysis and alternative regulation schemes, Energy Policy 108 (2017) 742-754.

[29] V. Bertsch, J. Geldermann, T. Lhn, What drives the profitability of household pv investments, self-consumption and selfsufficiency?, Applied Energy 204 (2017) 1 - 15.

[30] E. Nyholm, J. Goop, M. Odenberger, F. Johnsson, Solar photovoltaic-battery systems in swedish households-selfconsumption and self-sufficiency, Applied Energy 183 (2016)
$148-159$.

[31] A. Colmenar-Santos, S. Campíñez-Romero, C. Pérez-Molina, M. Castro-Gil, Profitability analysis of grid-connected photovoltaic facilities for household electricity self-sufficiency, Energy Policy 51 (2012) 749-764.

[32] J. Weniger, T. Tjaden, V. Quaschning, Sizing of residential PV battery systems, Energy Procedia 46 (2014) 78-87.

[33] J. Hoppmann, J. Volland, T. S. Schmidt, V. H. Hoffmann, The economic viability of battery storage for residential solar photovoltaic systems - A review and a simulation model, Renewable and Sustainable Energy Reviews 39 (2014) 1101-1118.

[34] J. D. Rhodes, C. R. Upshaw, C. B. Harris, C. M. Meehan, D. A. Walling, P. A. Navrátil, A. L. Beck, K. Nagasawa, R. L. Fares, W. J. Cole, H. Kumar, R. D. Duncan, C. L. Holcomb, T. F. Edgar, A. Kwasinski, M. E. Webber, Experimental and data collection methods for a large-scale smart grid deployment: Methods and first results, Energy 65 (2014) 462-471.

[35] D. Connolly, H. Lund, P. Finn, B. V. Mathiesen, M. Leahy, Practical operation strategies for pumped hydroelectric energy storage (PHES) utilising electricity price arbitrage, Energy Policy 39 (2011) 4189-4196.

[36] E. Barbour, D. Parra, Z. Awwad, M. C. González, Community energy storage: A smart choice for the smart grid?, Applied Energy 212 (2018) 489-497.

[37] W. E. Hart, J.-P. Watson, D. L. Woodruff, Pyomo: modeling and solving mathematical programs in python, Mathematical Programming Computation 3 (2011) 219-260.

[38] NREL, Distributed Generation Energy Technology Operations and Maintenance Costs, 2016.

[39] Electric Power Monthly, https://www.eia.gov/ electricity/monthly/epm_table_grapher.php?t= epmt_5_6_a, ???? Accessed: 2017-07-06.

[40] C. a. Hill, M. C. Such, D. Chen, J. Gonzalez, W. M. Grady, Battery energy storage for enabling integration of distributed solar power generation, IEEE Transactions on Smart Grid 3 (2012) 850-857.

[41] J. Widén, Improved photovoltaic self-consumption with appliance scheduling in 200 single-family buildings, Applied Energy 126 (2014) 199-212.

[42] R. Thygesen, B. Karlsson, Simulation of a proposed novel weather forecast control for ground source heat pumps as a mean to evaluate the feasibility of forecast controls influence on the photovoltaic electricity self-consumption, Applied Energy 164 (2016) 579-589.

[43] A. Habte, M. Sengupta, A. Lopez, Evaluation of the National Solar Radiation Database (NSRDB): 1998-2015, Technical Report, NREL (National Renewable Energy Laboratory (NREL), Golden, CO (United States)), 2017.

[44] A. Zucker, T. Hinchliffe, Optimum sizing of pv-attached electricity storage according to power market signals-a case study for germany and italy, Applied Energy 127 (2014) 141-155.

[45] A. Pena-Bello, M. Burer, M. K. Patel, D. Parra, Optimizing pv and grid charging in combined applications to improve the profitability of residential batteries, Journal of Energy Storage 13 (2017) 58-72.

[46] C. Heymans, S. B. Walker, S. B. Young, M. Fowler, Economic analysis of second use electric vehicle batteries for residential energy storage and load-levelling, Energy Policy 71 (2014) 2230 .

[47] B. Nykvist, M. Nilsson, Rapidly falling costs of battery packs for electric vehicles, Nature Climate Change 5 (2015) 329-332.

[48] E. L. Ratnam, S. R. Weller, C. M. Kellett, Scheduling residential battery storage with solar PV: Assessing the benefits of net metering, Applied Energy 155 (2015) 881-891.

[49] S. Agnew, P. Dargusch, Effect of residential solar and storage on 
centralized electricity supply systems, Nature Climate Change 5 (2015) 315.

[50] C. J. Barnhart, S. M. Benson, On the importance of reducing the energetic and material demands of electrical energy storage, Energy \& Environmental Science 6 (2013) 1083-1092.

[51] P. del Rio, P. Mir-Artigues, A cautionary tale: Spain's solar PV investment bubble, Technical Report, The Global Subsidies Initiative of the International Institute for Sustainable Development, 2014.

[52] International Energy Agency, Germany:Policies and Measures, 2016.

[53] T. Couture, K. Cory, State Clean Energy Policies Analysis (SCEPA) Project: An Analysis of Renewable Energy Feed-in Tariffs in the United States, Technical Report, National Renewable Energy laboratory, 2009. 